NBER WORKING PAPER SERIES

\title{
THE FISCAL AND WELFARE EFFECTS OF POLICY RESPONSES TO THE COVID-19 SCHOOL CLOSURES
}

\author{
Nicola Fuchs-Schündeln \\ Dirk Krueger \\ André Kurmann \\ Etienne Lalé \\ Alexander Ludwig \\ Irina Popova
}

Working Paper 29398

http://www.nber.org/papers/w29398

\author{
NATIONAL BUREAU OF ECONOMIC RESEARCH \\ 1050 Massachusetts Avenue \\ Cambridge, MA 02138 \\ October 2021
}

Fuchs-Schuendeln gratefully acknowledges financial support by the European Research Council through Consolidator Grant No. 815378, and by the DFG through a Leibnizpreis. Krueger thanks the National Science Foundation for financial support under grant SES-1757084. FuchsSchuendeln and Ludwig gratefully acknowledge financial support by NORFACE Dynamics of Inequality across the Life-Course (TRISP) grant: 462-16-120. We also thank Burbio and Safegraph for providing us with their data. The views expressed herein are those of the authors and do not necessarily reflect the views of the National Bureau of Economic Research.

NBER working papers are circulated for discussion and comment purposes. They have not been peer-reviewed or been subject to the review by the NBER Board of Directors that accompanies official NBER publications.

(C) 2021 by Nicola Fuchs-Schündeln, Dirk Krueger, André Kurmann, Etienne Lalé, Alexander Ludwig, and Irina Popova. All rights reserved. Short sections of text, not to exceed two paragraphs, may be quoted without explicit permission provided that full credit, including ( $)$ notice, is given to the source. 
The Fiscal and Welfare Effects of Policy Responses to the Covid-19 School Closures

Nicola Fuchs-Schündeln, Dirk Krueger, André Kurmann, Etienne Lalé, Alexander Ludwig, and Irina Popova

NBER Working Paper No. 29398

October 2021

JEL No. E24,E62

\begin{abstract}
Using a structural life-cycle model and data on school visits from Safegraph and school closures from Burbio, we quantify the heterogeneous impact of school closures during the Corona crisis on children affected at different ages and coming from households with different parental characteristics. Our data suggests that secondary schools were closed for in-person learning for longer periods than elementary schools (implying that younger children experienced less school closures than older children), and that private schools experienced shorter closures than public schools, and schools in poorer U.S. counties experienced shorter school closures. We then extend the structural life cycle model of private and public schooling investments studied in FuchsSchuendeln, Krueger, Ludwig and Popova (2021) to include the choice of parents whether to send their children to private schools, empirically discipline it with data on parental investments from the PSID, and then feed into the model the school closure measures from our empirical analysis to quantify the long-run consequences of the Covid-19 school closures on the cohorts of children currently in school. Future earnings- and welfare losses are largest for children that started public secondary schools at the onset of the Covid-19 crisis. Comparing children from the top- to children from the bottom quartile of the income distribution, welfare losses are ca. 0.8 percentage points larger for the poorer children if school closures were unrelated to income. Accounting for the longer school closures in richer counties reduces this gap by about $1 / 3$. A policy intervention that extends schools by 3 months (6 weeks in the next two summers) generates significant welfare gains for the children and raises future tax approximately sufficient to pay for the cost of this schooling expansion.
\end{abstract}

Nicola Fuchs-Schündeln

Goethe University Frankfurt

House of Finance

60323 Frankfurt

Germany

fuchs@wiwi.uni-frankfurt.de

Dirk Krueger

Economics Department

University of Pennsylvania

The Ronald O. Perelman Center

for Political Science and Economics

133 South 36th Street

Philadelphia, PA 19104

and NBER

dkrueger@econ.upenn.edu
André Kurmann

Drexel University

Lebow College of Business

3220 Market Street

Philadelphia, PA 19104

kurmann.andre@gmail.com

Etienne Lalé

University of Quebec at Montreal

C.P. 8888, Succ. centre ville

Department of Economics

H3C 3P8

Montreal (QC)

Canada

lale.etienne@uqam.ca 


\author{
Alexander Ludwig \\ Goethe University Frankfurt \\ House of Finance \\ Theodor-W.-Adorno-Platz 3 \\ D-60629 Frankfurt am Main \\ Alexander.ludwig@econ.uni-frankfurt.de \\ Irina Popova \\ Goethe University Frankfurt \\ House of Finance \\ Theodor-W.-Adorno-Platz 3 \\ D-60629 Frankfurt am Main \\ popova@econ.uni-frankfurt.de
}




\section{Introduction}

Governments around the world responded to the Covid-19 health crisis by shutting down economic and social activity, resulting in severe recessions and closed schools for much of 2020. The economic consequences of these lockdown measures triggered a large scientific and popular literature. As many countries are on the path of economic recovery from this crisis, focus is shifting from the short- to the long run consequences of the crisis. One such concern is the longrun impact of the significant loss of instructional time in schools during 2020-21 on children's education, earnings potential and future welfare.

In this paper we use a structural life-cycle model and data on school visits from Safegraph and school closures from Burbio to quantify the heterogeneous impact of school closures during the Covid-19 crisis on children affected at different ages and coming from households with different socio-economic parental characteristics. Our data suggests that secondary schools were closed for in-person learning for longer periods than elementary schools (implying that younger children experienced shorter school closures than older children), and that private schools experienced shorter closures than public schools, and schools in poorer U.S. counties experienced shorter school closures. We use these empirical facts as inputs for a positive and normative analysis of the long-run consequences of the observed Covid-19-induced school closures on the affected children. To do so, we extend the structural life cycle model of schooling investments studied in Fuchs-Schündeln, Krueger, Ludwig, and Popova (2021) to include the choice of parents whether to send their children to private schools, empirically discipline it with data on parental investments from the PSID, and then feed into the model the school closures measures from our empirical analysis to quantify the distributional consequences of the Covid-19 school closures.

We highlight two main findings. First, the aggregate losses of human capital, college attainment, the present discounted value of earnings and welfare are predicted to be large: for example, the present discounted value (PDV) of future gross earnings (after the current school children enter the labor market) falls by $1.73 \%$ and the welfare losses amount to $1 \%$ of permanent consumption. ${ }^{1}$ These results materialize despite the fact that parents optimally adjust their private time- and resource investment into their children, as well as inter-vivos transfers of wealth to their offspring.

Second, if all children had their schools closed for the same amount of time, then younger children, and those from disadvantaged backgrounds would suffer larger welfare losses, as our

\footnotetext{
${ }^{1}$ These losses are larger than in the first version of our previous paper because there we had assumed that school closures would last 25\% of the two year interval from March 2020 to March 2022. Our empirical work in this paper suggests that this assumption, made before the fall of 2020 , turned out to be too optimistic for the average school.
} 
previous work suggested. ${ }^{2}$ However, due to the significant empirically documented differences in the extent of the school closures these conclusions are partially overturned, and partially accentuated. The fact that, on average, secondary schools were closed much longer than primary schools leads to the finding that it is children just starting secondary school that endure the largest losses in their earnings capacity (a reduction of the PDV of earnings of more than 2\%) and welfare (a decline of $1.17 \%$ ).

With respect to socio-economic characteristics we make two key empirical observations. First, private schools, on average, were closed for significantly fewer days than public schools, and private schools are dis-proportionally frequented by children from parents with higher socio-economic characteristics (in the model, associated with higher education, higher wealth and being married). However, focusing on only public schools, these were closed for longer in counties with lower average income.

The quantitative model then maps these empirical findings into the expected differential welfare consequences for children. Those attending private schools on average lose half a percentage point less welfare (measured in terms of permanent consumption), relative to those children attending public schools, accentuating the larger welfare losses poorer children have in the absence of differential school closures. Within public schools, however the income gradient of welfare losses goes in the opposite direction since poorer areas in the U.S., especially in the South but also the Midwest, saw shorter school closures on average than the more affluent regions on both coasts. Of course, children from poorer households are still worse off and might have been affected more severely from the Covid-19 crisis along many other dimensions, but the fact that, again on average, their schools were locked for shorter periods of time than the schools in richer counties implies that the losses in human capital, lifetime earnings, and ultimately, welfare, are more benign than those children from richer families (or more precisely, residing in richer counties).

Finally, and motivated by the significant and heterogeneous human capital and welfare losses we consider potential policy interventions designed to mitigate the instructional losses from the Covid-19 crisis. One such proposal is to keep schools open for parts of future summer periods to make up the lost time. In the model, since we have a well-defined cost of schooling and model-predicted consequences of additional schooling on future human capital, earnings and taxes, we can ask whether such a measure is a positive net present discounted value proposition for households. Furthermore, since a policy intervention that keeps all schools open might not be

\footnotetext{
${ }^{2}$ This result is driven by the two key properties of the human capital production function, as emphasized by Cunha and Heckman (2007): self productivity (holding current investment constant, larger human capital today leads to higher human capital tomorrow) and dynamic complementarity: the marginal product of investment into human capital today is increasing in the already accumulated stock of human capital). As a consequence, the loss of learning experienced by younger children accumulates over time, leading to larger human capital losses for these younger children, relative to their older brothers.
} 
feasible due to scarcity in the availability of teachers or physical infrastructure, we also investigate for which group of students such a policy intervention is especially promising, both in terms of the budgetary consequences for the government and in terms of welfare for the individual students. We find that for the average child the welfare gains from expanded schooling are significant $(0.21 \%$ in terms of consumption equivalent variation), and induce an increase in future revenues from labor income and consumption taxes approximately sufficient to pay for the entire cost of the reform; that is, the reform is essentially budget-neutral. Finally, the welfare gains from the expansion are highest for children from income-poor households, whereas the fiscal consequences for the government look most favorable if the intervention is targeted to children from the most affluent households.

The remainder of the paper proceeds as follows. In the next section we briefly relate our model to the existing literature. Section 3 describes the data we use to construct measures of school closures and the empirical measures of school closures we will employ in the structural model. That model is spelled out in Section 4 and calibrated in Section 5. We present the results on the differential welfare consequences of the school closures in Section 6 and Section 7 contains the counterfactual policy analysis. Section 9 concludes. Details about the construction of the data as well as the dynamic programs in the model can be found in the appendix.

\section{Related Literature}

Our paper is part of the massive literature on the consequences of the Covid-19 epidemic on the economy. The early literature focused on short-run predictions of the evolution of the health crisis and the economic recession, triggered by a fall in the healthy work force and its desire to work in risky sectors, the demand for goods and services induced by falling household incomes as well as massive government-mandated economic lockdowns. Representative contributions in economics include Atkeson (2020), Fernandez-Villaverde and Jones (2020), Greenstone and Nigam (2020) and Alemán et al. (2021) on the health side and Eichenbaum et al. (2020) as well as Krueger et al. (2020), Moll et al. (2020) on the economic side. A subset of this literature (see e.g. Argente et al. (2020), Acemoglu et al. (2020), Glover et al. (2020), Brotherhood et al. (2020)) has considered optimal lockdown policies, where the main benefit of shutting down part of the economy is a slower transmission of the virus, and the main cost is modeled as the reduction of economic activity and thus incomes of individuals of current working age. The potential impact of closing schools as part of the lockdown is not considered in these papers.

Complementary to this literature, our paper takes a longer-run perspective and analyzes the consequences of one specific aspect of the crisis, school closures, that initially did not receive much attention, likely due to the fact that the main costs associated with this non-pharmacological 
intervention accrue mostly in the medium to long-run when the cohort of school children affected by school closures enter the higher education- or labor market. In our previous work (Fuchs-Schündeln et al., 2021) we used a structural life cycle model to quantify the impact of a hypothetical school closure for 12 months on average human capital accumulation, lifetime earnings and welfare. In the current paper we build on this framework, but turn to micro data from Safegraph and Burbio to measure the actual length of school closures, and crucially, argue that there is significant heterogeneity across school types (public versus private), grade level (elementary versus secondary), and parental backgrounds in the extent to which schools were closed. This analysis is motivated by an emerging body of evidence that learning achievement during the pandemic was substantially lower than in prior years, suggesting that the virtual instruction brought about by school closures was much less effective than traditional in-person instruction. ${ }^{3}$

Therefore, our paper combines the structural literature modeling human capital accumulation in children of school age and public education (see e.g. Cunha et al. (2006), Cunha and Heckman (2007), Cunha et al. (2010), Caucutt and Lochner (2020), Kotera and Seshadri (2017), Lee and Seshadri (2019), Yum (2020), Caucutt et al. (2020), Jang and Yum (2021) and especially Agostinelli et al. (2020)) with the empirical literature that has compiled direct data on school closures or estimated the extent of school closures indirectly. ${ }^{4}$

The Safegraph visits data employed in this paper has been used by other studies to measure social distancing behavior, the impact of the pandemic on in-person services, and industry affiliation of particular businesses (e.g. Allcott et al. (2020), Goolsbee and Syverson (2021), or Kurmann et al. (2021) among many others). The papers closest to ours are Chernozhukov et al. (2021) and Bravata et al. (2021) who estimate the association between changes in Safegraph visits to schools and the spread of Covid-19 at the county level, as well as Parolin and Lee (2021) who use the Safegraph data to construct a school closure index and, like us, match the Safegraph data with information from NCES and other sources to relate their school closure index to grade level (elementary versus secondary) and a variety of socioeconomic indicators. ${ }^{5}$ Different from these papers, we build on the approach by Kurmann and Lalé (2021) and combine the Safegraph visits data with data on learning modes by Burbio to estimate a mapping of changes in school visits with learning modes. This allows us to construct a measure of effective schooling time by

\footnotetext{
${ }^{3}$ See for example Dorn et al. (2021), Kogan and Lavertu (2021), or Lewis et al. (2021).

${ }^{4}$ A complementary, empirically oriented literature, assesses the importance of instruction time or schooling inputs for student outcomes, see e.g. Lavy (2015), Carlsson et al. (2015), Rivkin and Schimann (2015), Fitzpatrick et al. (2011), Pischke (2007) and Jaume and Willén (2019).

${ }^{5}$ Chernozhukov et al. (2021) also use data from MCH Strategy on different school learning modes to predict Covid infection rates.
} 
school type (public versus private school), grade level, and parental background, which in turn constitutes a crucial input for our model simulations. ${ }^{6}$

\section{Data}

In this section we describe the data and procedures to measure effective schooling time during the pandemic. We start with the Safegraph data, how we measure changes in visits to schools, and how we match the schools with records from the National Center for Education Statistics (NCES) to obtain information on different school characteristics. Then, we show how we use Burbio data on school learning modes to map changes in school visits to effective in-person learning. Finally, we present empirical results by school characteristic that serve as input for the structural model simulations.

\subsection{Measuring Effective In-person Learning}

\subsubsection{Safegraph School Visit Data}

The main source of information for measuring the length of effective schooling time comes from Safegraph, which provides data for over 6 million Places of Interest (POls) for the U.S. using cell phone pings. ${ }^{7}$ From this large set of POls we extract establishments with North American Industry Classification System (NAICS) code 611110 ("Elementary and Secondary Schools") that are present in Safegraph's Weekly Patterns, which provides data on weekly visits by POI. We then match Safegraph's POIs with NAICS code 611110 by school name and address to public and private schools from the Department of Education's National Center for Education Statistics (NCES), resulting in about 102,500 high-quality matches of schools with Safegraph data on weekly visits. Appendix B provides details of the matching procedure and results. Relative to the universe of schools in the NCES, we lose about 22,000 schools, but the matched school sample remains highly representative of the overall population of schools in terms of socioeconomic and geographic makeup.

\subsubsection{Measuring Changes in School Visits}

The Safegraph data provides weekly visit counts for each school by dwell times. There are $D=7$ dwell time intervals (less than 5, 5 to 10,11 to 20,21 to 60,61 to 120,121 to 240 , more than

\footnotetext{
${ }^{6}$ See Kurmann and Lalé (2021) for details on the estimation approach and a more in-depth analysis of the predictors of effective schooling time.

${ }^{7} \mathrm{~A}$ cell phone ping is the process of determining the location of a cell phone at any given point in time.
} 
240 minutes), Denoting weekly visits counts as $v_{j, t}(d)$ for $d=1, \ldots, D$, the total visits count for school $j$ in week $t$ is $v_{j, t}=\sum_{d=1}^{D} v_{j, t}(d)$.

As Figure 6 in the appendix shows, prior to the pandemic, both aggregate total visit counts and aggregate visits longer than 240 minutes per day decline markedly during the weeks of Thanksgiving, Christmas, and Summer break. In addition and in line with the public health emergency on March 13, 2020, both visits series drop precipitously during the week of March 15 to March 21, 2020 and remain substantially lower thereafter. Appendix Figure 6 also shows that there is substantial week-to-week variation in visit counts, as well as an overall upward trend in visit counts. The trend could be due to increased cell phone usage by students and teachers, but it could also be due to an increase in the number of cell phone devices sampled by Safegraph. To control for the latter and reduce the high frequency variation that is driven by changes in Safegraph's sample size, we normalize visit counts by the weekly counts of SG devices at the county level.

As opposed to Chernozhukov et al. (2021), Bravata et al. (2021), and Parolin and Lee (2021) who consider year-over-year changes in weekly Safegraph visits to schools, we construct changes in visits relative to average visits prior to the pandemic. This has the advantage that we do not need to correct for holidays and other idiosyncratic variations in visits that fall on different weeks across years, thereby reducing measurement error. The construction involves 4 steps:

1. For each school $j$, we define weights $\omega_{j}(d)$ as:

$$
\omega_{j}(d)=\frac{\sum_{t=t_{0}}^{t_{1}} v_{j, t}(d)}{\sum_{t=t_{0}}^{t_{1}} v_{j, t}},
$$

where $t=t_{0}, \ldots, t_{1}$ denotes the base period (beginning of November 2019 through the end of February 2020, excluding the weeks of Thanksgiving, Christmas and the New Year); and $\omega_{j}(d)$ measures the contribution of a dwell time $d$ to school $j$ 's raw visits counts during the base period.

2. Using the weights, we measure weighted weekly visits at school $j$ in week $t$ as

$$
\widetilde{v}_{j, t}=\frac{1}{n_{c(j), t}} \sum_{d=1}^{D} \omega_{j}(d) v_{j, t}(d),
$$

where $n_{c(j), t}$ denotes the normalization by SG devices during week $t$ in county $c(j)$ in which the school $j$ is located. As discussed above, this normalization reduces the impact of changes in the number of cell phone devices sampled by Safegraph on visit counts. 
3. Given weighted school visits in week $t$, we measure the percent change in school visits as

$$
d_{j, t}=\frac{\widetilde{v}_{j, t}-\widetilde{v}_{j, 0}}{\widetilde{v}_{j, 0}} \times 100,
$$

where $\widetilde{v}_{j, 0}=\frac{1}{t_{1}-t_{0}+1} \sum_{t=t_{0}}^{t_{1}} \widetilde{v}_{j, t}$ is the mean value of $\widetilde{v}_{j, t}$ during the base period.

4. In order to reduce noise in $d_{j, t}$, we top-code $d_{j, t}$ at $100 \%$. In addition, if in any $t$ outside of the base period $d_{j, t}>25$ while $d_{j, t-1} \leq 25$ and $d_{j, t+1} \leq 25$, we replace $d_{j, t}$ by the average of $d_{j, t-1}$ and $d_{j, t+1}$. This adjustment implements the assumption that during the school year 2020-21, schools did not reopen for only one week at a time.

In order to further reduce measurement error, we drop schools with sparse or very noisy visit data and apply weights to ensure that the remaining sample of roughly 70,000 schools remains representative of the full sample of schools in the U.S. See Appendix B.1 for details on the sample selection criteria and weighting procedure.

Figure 1 presents histograms of the distribution of changes in school visits $d_{j, t}$ during three subperiods (averaged over the weeks within a given subperiod). The figure clearly shows that relative to the pre-pandemic period, school visits declined massively during March-May 2020, and were still significantly lower during September-December 2020 and (less so) during January-May 2021.

Figure 1: Distribution of changes in school visits for selected subperiods

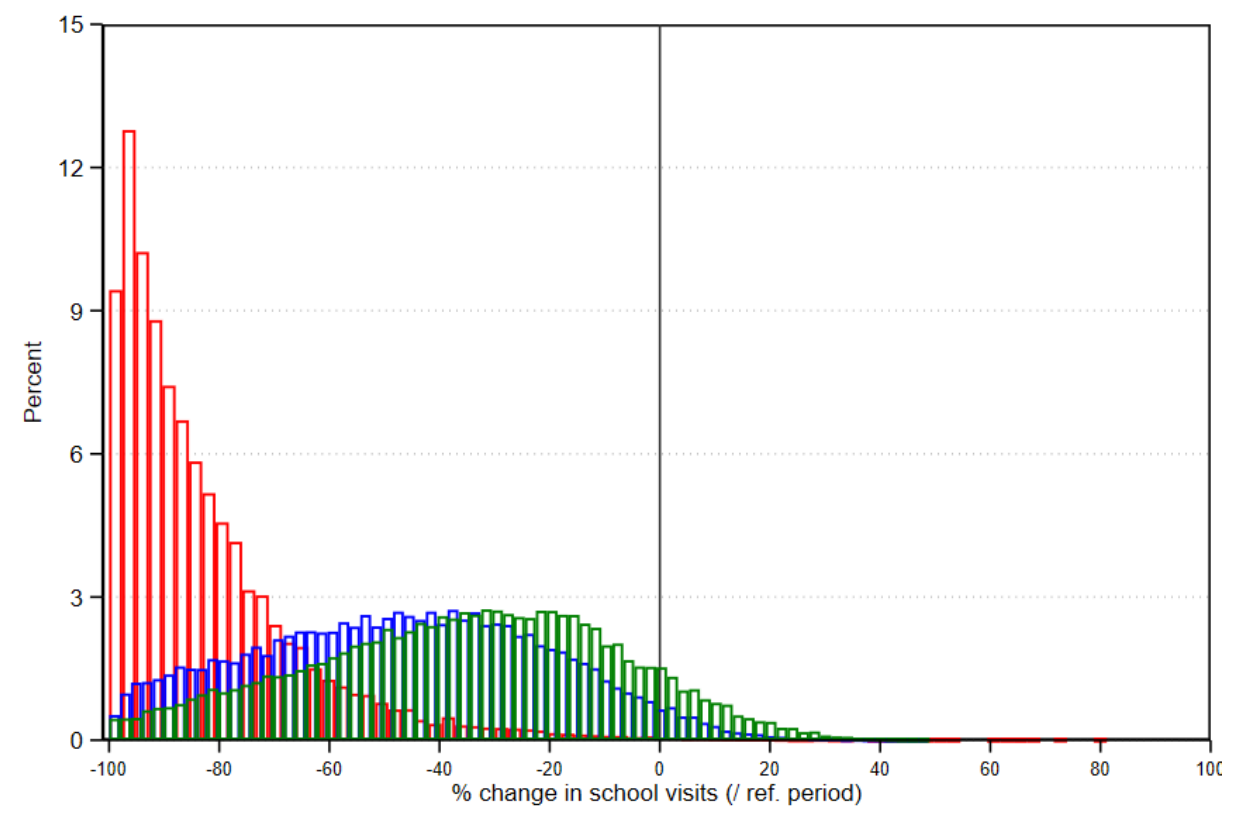

Mar-May 2020

Sep-Dec 2020

Jan-May 2021 
Figures 2 to 4 show the geographical variation in county average school visit changes for the three subperiods. During March-May 2020, school visits in most counties were 75 to 100 percent below pre-pandemic levels, without much regional variation. During September-December 2020, in contrast, we observe substantial variation in school visits across different regions, as many schools in the Southern, Midwestern, and Central Northern parts of the U.S. reopened while schools in the Western and Eastern parts remained largely closed. During January-May 2021, the situation becomes again more even, with school visits returning towards pre-pandemic levels in most counties except on the West Coast, parts of the East Coast, and a few other counties across the U.S.

Figure 2: Average change in school visits by county: March-May 2020

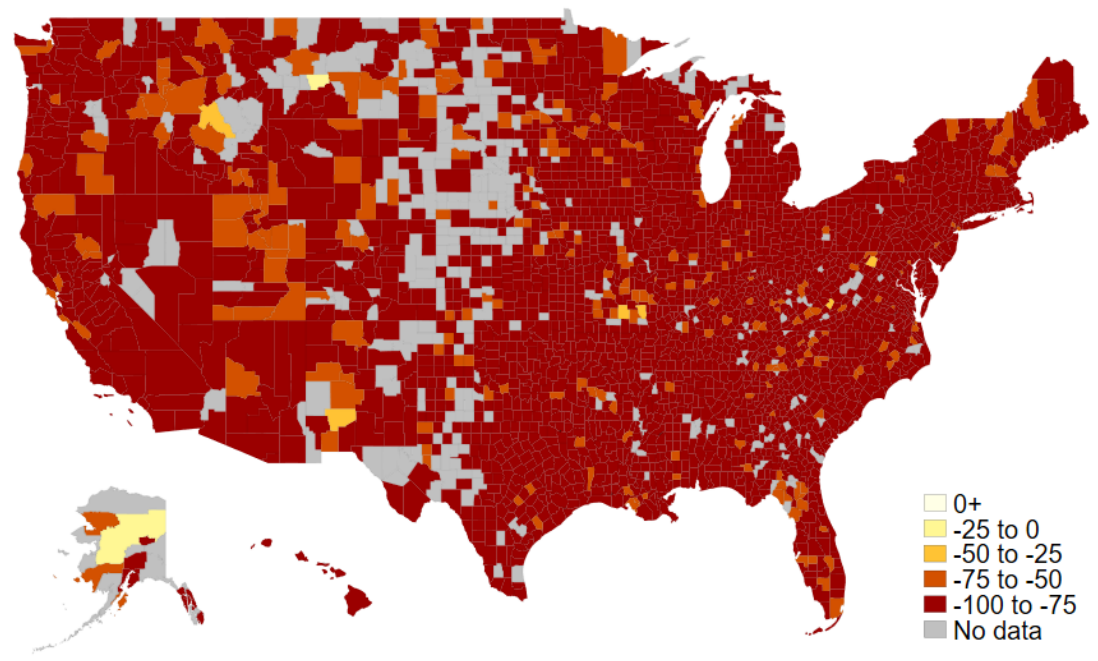

Figure 3: Average change in school visits by county: September-December 2020

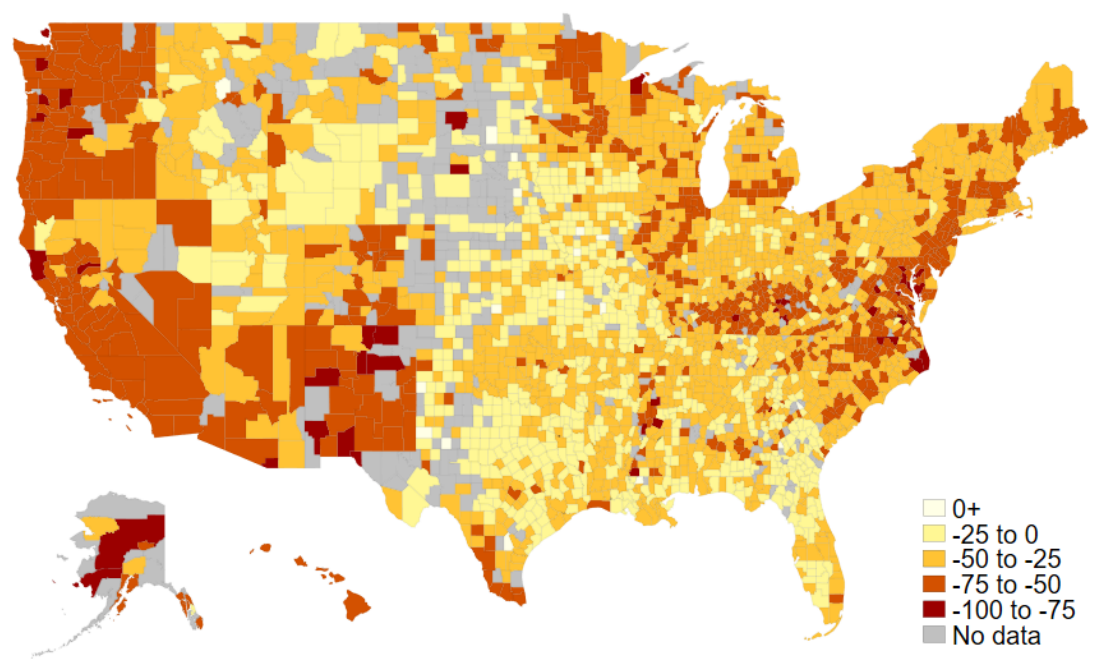


Figure 4: Average change in school visits by county: January-May 2021

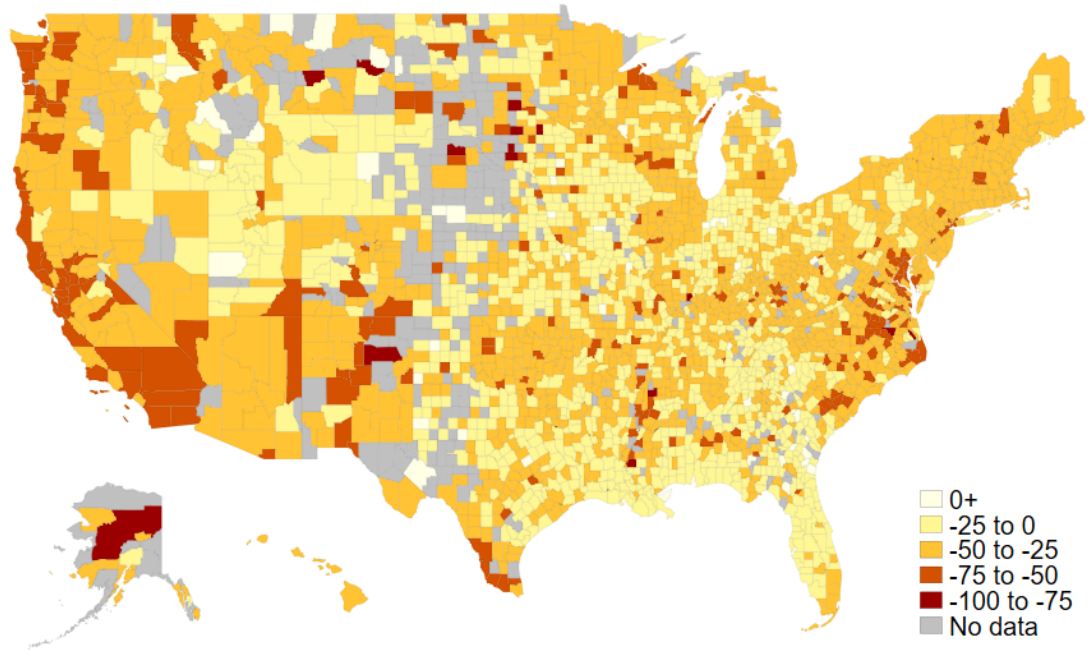

\subsubsection{From Changes in School Visits to Effective In-person Learning}

In order to map the change in school visits at the individual school level into a measure of effective in-person learning, we relate our school visit data to estimates of school learning mode from Burbio. Burbio is a private company that collects data for 1,200 public school districts representing 47 percent of U.S. K-12 student enrollment in over 35,000 schools in all 50 states. The data is aggregated to the county level and primarily used for commercial purposes, but the company generously shared the data with us and other researchers. The information on learning mode consists of weekly indicators between mid-August 2020 and mid-June 2021 that for each county provide the percent of public school students engaged in either Traditional, Hybrid, or Virtual learning mode. Traditional means that students attend in-person school every day of the week; Hybrid means that students attend 2-3 days per week in-person; and Virtual means that students do not attend school in person. Appendix B.2 contains more details about the Burbio data.

We construct county-level averages $\bar{L}_{c}$ of the fractions that public school students spent in learning mode $L \in\{$ traditional,hybrid,virtual $\}$ between week $t_{0}$ and week $t_{n}$

$$
\bar{L}_{c}=\frac{1}{T} \sum_{t=t_{0}}^{t_{n}} L_{c, t},
$$

where $L_{c, t}$ denotes the percent of students in county $c$ who spent week $t$ in learning mode $L$; and $T=t_{n}-t_{0}+1$ is the number of weeks considered. For instance, $\bar{L}_{c}=0.33$ for $L=$ traditional computed from September 2020 to June 2021 means that public school students in county $c$ spent one third of the school year 2020-2021 in traditional learning mode. 
Next, we define the fraction of the school year that students in county $c$ effectively spent in in-person learning mode as $\bar{T}_{c}^{*}=\bar{T}_{c}+\gamma \bar{H}_{c}$ and the fraction effectively spent in virtual learning mode as $\bar{V}_{c}^{*}=\bar{V}_{c}+(1-\gamma) \bar{H}_{c}$, where $\gamma$ measures the fraction of total student-days that are spent in person when the learning mode is hybrid. We then relate these measures to the change in Safegraph school visits with the following linear regression

$$
\bar{T}_{c}^{*}=\alpha+\beta \bar{d}_{c}+\varepsilon_{c}
$$

or equivalently,

$$
\bar{T}_{c}=\alpha+\beta \bar{d}_{c}+\gamma \bar{H}_{c}+\varepsilon_{c},
$$

where $\bar{d}_{c}$ is the student-weighted average of changes in school visits across schools in county $c$. The regression tells us not only how a given change in school visits maps into effective in-person learning relative to its pre-pandemic level, $\bar{T}_{c}^{*}$, but also the average proportion $\gamma$ of in-person learning when students are in Hybrid mode. Since $\bar{T}_{c}+\bar{H}_{c}+\bar{V}_{c}=100$ and thus $\bar{V}_{c}^{*}=100-\bar{T}_{c}^{*}$, the regression also tells us how a given change in school visits maps into effective virtual learning mode $\bar{V}_{c}^{*}$.

We estimate (2) using Burbio and Safegraph data for Fall 2020 only. The reason we are not using data for Winter and Spring 2021 is that during this period, school districts increasingly moved away from virtual learning. As a result, changes in traditional learning $\bar{T}_{c}$ are close to linear with hybrid learning $\bar{H}_{c} \approx 100-\bar{T}_{c}$. In a regression context, this implies $\gamma \rightarrow 1$ and $\beta \rightarrow 0$ since $\bar{d}_{c}$ is subject to idiosyncratic noise. During Fall 2020, in contrast, there are changes across all three learning modes, which enables us to identify the mapping between $\bar{T}_{c}$ and $\bar{d}_{c}$, controlling for $\bar{H}_{c}$.

Table 1 reports the results of the estimation. In column (1), we consider all counties for which we have data on both Burbio learning modes and Safegraph school visits (3,049 out of 3,124 available counties in Burbio). The sample represents almost 95 percent of all public-school students in the U.S. The mapping between the different variables is tightly estimated, with a $R^{2}$ of over 0.5 and highly significant coefficients. A 1 percentage point decline in school visits reduces the fraction of weeks spent in effective in-person learning by 1.14 percentage points, and the estimated fraction of hybrid learning mode spent in in-person learning mode is 0.5 or 2.5 days out of a 5 day school week. Closer inspection of the data reveals that the resulting relationship between effective in-person learning mode $\bar{T}_{c}^{*}$ and change in school visits is indeed well represented by a linear function. Finally, the estimated intercept is 101.67, close to the predicted value of 100 when school is fully in-person (i.e. $\bar{d}_{c}=0$ and $\bar{H}_{c}=0$ ). 
Table 1: Regression of traditional learning against changes in school visits

\begin{tabular}{lcccc}
\hline & $(1)$ & $(2)$ & $(3)$ & $(4)$ \\
\hline & & & & \\
Change in Safegraph visits $\bar{d}_{c}$ & $1.14^{* * *}$ & $1.12^{* * *}$ & $1.13^{* * *}$ & $1.15^{* * *}$ \\
& $(0.01)$ & $(0.01)$ & $(0.01)$ & $(0.01)$ \\
Burbio's $\bar{H}_{c}$ & $-0.50^{* * *}$ & $-0.49^{* * *}$ & $-0.48^{* * *}$ & $-0.43^{* * *}$ \\
& $(0.01)$ & $(0.01)$ & $(0.01)$ & $(0.01)$ \\
Intercept & $101.67^{* * *}$ & & & \\
& $(0.76)$ & & & \\
Adjusted $R^{2}$ & 0.513 & 0.513 & 0.522 & 0.589 \\
& & & & \\
\hline$N$ of counties & 3,049 & 3,049 & 2,438 & 794 \\
$N$ of students (in thousands) & 48,013 & 48,013 & 47,250 & 40,485 \\
\% of all public-school students & 94.5 & 94.5 & 92.9 & 79.6 \\
\hline
\end{tabular}

Notes: Safegraph and Burbio data for Fall term 2020 (weeks of September 27 - October 3 to December 13 - December 19, excluding the week of Thanksgiving). All regressions are weighted by student enrollment at the county level. $\left(^{*}\right)$ In columns (2)-(4) the intercept is constrained to 100.

As robustness checks, in column (2) we restrict the intercept to 100 and rerun the regression, while in columns (3) and (4), we reduce the sample to the counties with at least 5 schools for which we have data, respectively to the counties in the top-25 percent of the population distribution. The results are strikingly robust across the different specifications: a 1 percentage point decline in school visits reduces the fraction of weeks spent in effective in-person learning by 1.14 percentage points, and Hybrid learning mode is estimated to correspond to a fraction of 0.43 to 0.49 of in-person learning mode.

In sum, the regressions confirm that there is a tight linear relationship between change in school visits and effective in-person learning. We therefore feel confident to use this mapping to infer effective schooling time at the individual school level.

\subsection{Effective schooling time by school characteristic}

In the model simulations below, effective schooling time over the two-year period between Summer 2019 and Summer 2021 will be an important input to quantify the consequences of learning loss during the pandemic. We proceed as follows to infer this value from our data on school visit changes. According to the NCES table of "Number of instructional days and hours in the school year" (https://nces.ed.gov/programs/statereform/tab5_14.asp), there are 180 instructional days per year in almost every state. Dividing this number by 5 (since weekends are 
excluded from the counts), we obtain 36 weeks of potential schooling per year. ${ }^{8}$ Equivalently, we have 72 weeks of potential schooling for the two-year period between Summer 2019 and Summer 2021. For the 25 weeks between September 2019 and mid-March 2020 that precede the pandemic, we set effective school time to 100 percent. For the remaining 11 weeks of the 20192020 school year (week of Mar 15 - Mar 21 through the week of May 24 - May 30) and the 36 weeks of the 2020-2021 school year, we calculate effective schooling time using the estimates in Table 1; i.e. for the set of schools with a certain characteristic $k$ (e.g. public vs private schools), we take the average student-weighted change in school visits $\bar{d}_{k}$ and calculate effective schooling time as $\hat{\bar{T}}_{k}^{*}+\phi \hat{\bar{V}}_{k}^{*}$, where $\hat{\bar{T}}_{k}^{*}=100+\hat{\beta} \bar{d}_{k}, \hat{\bar{V}}_{k}^{*}=-\hat{\beta} \bar{d}_{k}$, and $\phi \in\left[\begin{array}{ll}0 & 1\end{array}\right]$ denotes the effectiveness of virtual learning. Thus, our estimate of effective schooling time during the two-year period from 2019 to 2021 as a percent of what schooling time would have been without the pandemic is

$$
\frac{1}{72}\left(25 \times 100+(72-25)\left(\hat{\bar{T}}_{k}^{*}+\phi \hat{\bar{V}}_{k}^{*}\right)\right)
$$

Table 2 shows effective schooling time by school characteristics under different assumptions about the effectiveness of virtual learning. Across all schools in the sample, school visits declined by student-weighted average of 55 percent over the period from mid-March 2020 through the end of the 2020-21 school year. If virtual learning has zero effectiveness, then this decline in school visits together with the estimated coefficients in Table 1 between 1.12 and 1.15 implies an estimated loss of effective schooling time of $(1.12+1.15) / 2 \times-55 \%=-62.5 \%$ during that period. Consequently, the effective schooling time over the two-year period from Summer 2019 to Summer 2021 equals $59.2 \%$, which is shown in the top-left corner of the first panel of Table 2. If instead, virtual learning has a $25 \%$ effectiveness, the implied effective schooling time equals $69.4 \%$, as shown in the top-left corner of the second panel of Table 2. Finally, if virtual learning has a $50 \%$ effectiveness, the implied effective schooling time equals $79.6 \%$, as shown in the top-left corner of the third panel of Table 2.

The remainder of Table 2 reports results of the same calculations separately for public versus private schools and for elementary versus secondary schools. Private schools experience on average smaller drops in school visits during the pandemic than public schools. Similarly, elementary schools experience smaller drops in school visits than secondary schools (either private or public, although for public schools the difference between elementary and secondary schools is larger). As a result, effective schooling time is the highest for private elementary schools and the lowest for secondary public schools.

\footnotetext{
${ }^{8}$ As an illustration, the 36 weeks of potential schooling can be obtained by taking the 52 weeks in a year and subtracting 13 weeks for summer break and 3 weeks for winter break, Thanksgiving, and other holidays.
} 
Table 2: Estimates of effective schooling time over the 2019-2021 period

\begin{tabular}{|c|c|c|c|}
\hline & \multicolumn{3}{|c|}{ Without virtual learning } \\
\hline & All & Elementary & Secondary \\
\hline \multirow[t]{2}{*}{ All } & 59.2 & 62.2 & 52.3 \\
\hline & {$[58.3,60.1]$} & {$[61.4,63.1]$} & {$[51.2,53.3]$} \\
\hline \multirow[t]{2}{*}{ Public schools } & 58.5 & 62.0 & 51.7 \\
\hline & {$[57.6,59.5]$} & {$[61.1,62.8]$} & {$[50.6,52.8]$} \\
\hline \multirow[t]{4}{*}{ Private schools } & 65.9 & 66.2 & 62.1 \\
\hline & {$[65.2,66.7]$} & {$[65.5,67.0]$} & {$[61.2,62.9]$} \\
\hline & \multicolumn{3}{|c|}{ With virtual learning, $25 \%$ effectiveness } \\
\hline & All & Elementary & Secondary \\
\hline \multirow[t]{2}{*}{ All } & 69.4 & 71.7 & 64.2 \\
\hline & {$[68.7,70.1]$} & {$[71.0,72.3]$} & {$[63.4,65.0]$} \\
\hline \multirow[t]{2}{*}{ Public schools } & 68.9 & 71.5 & 63.8 \\
\hline & {$[68.2,69.6]$} & {$[70.8,72.1]$} & {$[63.0,64.6]$} \\
\hline \multirow[t]{4}{*}{ Private schools } & 74.4 & 74.7 & 71.6 \\
\hline & {$[73.9,75.0]$} & {$[74.1,75.2]$} & {$[70.9,72.2]$} \\
\hline & \multicolumn{3}{|c|}{ With virtual learning, $50 \%$ effectiveness } \\
\hline & All & Elementary & Secondary \\
\hline \multirow[t]{2}{*}{ All } & 79.6 & 81.1 & 76.1 \\
\hline & {$[79.1,80.1]$} & {$[80.7,81.5]$} & {$[75.6,76.7]$} \\
\hline \multirow[t]{2}{*}{ Public schools } & 79.3 & 81.0 & 75.9 \\
\hline & {$[78.8,79.7]$} & {$[80.6,81.4]$} & {$[75.3,76.4]$} \\
\hline \multirow[t]{2}{*}{ Private schools } & 83.0 & 83.1 & 81.0 \\
\hline & {$[82.6,83.3]$} & {$[82.7,83.5]$} & {$[80.6,81.5]$} \\
\hline
\end{tabular}

Notes: The upper panel reports the share of potential schooling time over the 2019-2021 period that was effectively spent in the classroom. The middle and lower panel reports the share of potential schooling time over the 2019-2021 period that was effectively devoted to learning, assuming that virtual learning is respectively $25 \%$ and $50 \%$ as effective as in-person learning. In each cell, the bracketed numbers correspond to lower and upper bounds based on the Burbio estimates reported in Table 1, and the point estimate is computed as the mid-point of the interval. 
Table 3: Estimates of effective schooling time: High vs. low household income

\begin{tabular}{lccc}
\hline & \multicolumn{3}{c}{ Without virtual learning } \\
\hline \multirow{2}{*}{ Top quartile of household income } & All & Elementary & Secondary \\
& 54.5 & 58.0 & 46.8 \\
Bottom quartile of household income & {$[53.5,55.5]$} & {$[57.1,58.9]$} & {$[45.6,48.0]$} \\
& 63.9 & 66.6 & 58.2 \\
& {$[63.1,64.7]$} & {$[65.9,67.3]$} & {$[57.2,59.1]$} \\
\hline & With virtual learning, 25\% effectiveness \\
\hline \multirow{2}{*}{ Top quartile of household income } & All & Elementary & Secondary \\
& 65.9 & 68.5 & 60.1 \\
Bottom quartile of household income & {$[65.1,66.6]$} & {$[67.8,69.2]$} & {$[59.2,61.0]$} \\
& 72.9 & 74.9 & 68.6 \\
& {$[72.3,73.5]$} & {$[74.4,75.5]$} & {$[67.9,69.3]$} \\
\hline & \multicolumn{4}{|c}{} \\
\hline \multirow{2}{*}{ Top quartile of household income } & With virtual learning, 50\% effectiveness \\
\hline \multirow{2}{*}{ Bottom quartile of household income } & 77.2 & Elementary & Secondary \\
& {$[76.7,77.7]$} & $778.5,79.5]$ & {$[72.8,74.0]$} \\
& 82.0 & 83.3 & 79.1 \\
& {$[81.6,82.4]$} & {$[82.9,83.7]$} & {$[78.6,79.5]$}
\end{tabular}

Notes: The upper panel reports the share of potential schooling time over the 2019-2021 period that was effectively spent in the classroom. The middle and lower panel reports the share of potential schooling time over the 2019-2021 period that was effectively devoted to learning, assuming that virtual learning is respectively $25 \%$ and $50 \%$ as effective as in-person learning. In each cell, the bracketed numbers correspond to lower and upper bounds based on the Burbio estimates reported in Table 1, and the point estimate is computed as the mid-point of the interval.

Table 3 reports results for schools located either in a county ranked in the top or the bottom quartile of the household income distribution. Perhaps somewhat surprisingly, schools in affluent counties generally experienced a larger decline in school visits and therefore lower effective schooling time during the pandemic than schools in counties with low household income. As shown in separate work by Kurmann and Lalé (2021), this difference is primarily due to the fact that the affluent counties are disproportionally located in states where schools remained closed or did not return to full in-person instruction. Within quartiles of average household income, the difference in effective schooling time between elementary and secondary schools remains similar as reported in Table 2 .

To sum up, the results in this section reveal sizable differences in effective schooling time across different types of schools. In the model-based analysis that follows, we will exploit this variation in 
effective schooling time to analyze the extent to which they result in heterogeneous earnings- and welfare losses for children in different school types, grades and with different household income.

\section{A Quantitative Life Cycle Model with Education Choices}

After having measured the extent and variation of school closures in the data, we now describe the structural life cycle model that we will employ to measure the heterogeneous consequences for lifetime earnings, welfare, and taxes paid of the school closures we observed empirically in the previous section. We first describe the demographics, timing, stochastic structure, endowments, preferences and government policy and then formulate the individual decision problems recursively, since this is the representation we will compute. Since this model shares many features with the one used in Fuchs-Schündeln et al. (2021) we will focus on the novel features relative to their model when presenting the recursive representation of the model, relegating a complete account of all other dynamic programming problems of the model to Appendix A.

\subsection{Individual State Variables, Risk, and Economic Decisions}

We model individuals living in discrete time and denote the current period by $t$. Ours is a partial equilibrium model where individuals of two generations, a parent generation and a children generation, live through a full life cycle. When children live in the parental household, the key education investment decisions (whether to send the child to private or public school, and how much time and resources to invest into the child during her schooling years) are being taken by parents. The child generation makes one key decision upon becoming an independent household: equipped with inter-vivos transfers of the parent it decides what tertiary education, if any, to attain. After this decision this generation lives through a standard consumption-saving life cycle model; the same is true for the parental generation after the children have left the household. The timing and events in the model are summarized in Figure 5; we now turn to a more detailed description of the underlying heterogeneity of individuals and of each phase of the life cycle they undergo.

Individuals are part of either the child or parental generation, $k \in\{c h, p a\}$. They differ in their marital status $m \in\{s i, m a\}$ for single and married, their age $j \in\{0, \ldots, J<\infty\}$, where a model period and age $j$ spans two years in real time, their asset position $a$, their current human capital $h$, their education level $e \in\{n o, h s, c o\}$ for no higher education (no high school completion), high school attendance and completion, college attendance and completion, and idiosyncratic productivity risk modeled as a two state Markov process with state vector $\eta \in$ $\left\{\eta_{l}, \eta_{h}\right\}$, where $\eta_{l}$ is low and $\eta_{h}$ is high labor productivity, and transition matrix $\pi\left(\eta^{\prime} \mid \eta\right)$ and a 
transitory shock $\varepsilon \in\left\{\varepsilon_{1}, \ldots, \varepsilon_{n}\right\}$. Parents decide to send their children either to public or private $s c h o o l, s \in\{p u, p r\}$, and school type then becomes a state variable of the child. All individual state variables and the range of values they can take are summarized in Table 4.

Table 4: State Variables

\begin{tabular}{lcc}
\hline \hline State Var. & Values & Interpretation \\
\hline$k$ & $k \in\{c h, p a\}$ & Generation \\
$m$ & $m \in\{s i, m a\}$ & Marital Status \\
$j$ & $j \in\{0,1, \ldots, J\}$ & Model Age \\
$a$ & $a \geq-\underline{a}(j, s, k)$ & Assets \\
$s$ & $s \in\{p u, p r\}$ & School Type \\
$h$ & $h>0$ & Human Capital \\
$e$ & $e \in\{n o, h i, c o\}$ & Education \\
$\eta$ & $\eta \in\left\{\eta_{l}, \eta_{h}\right\}$ & Persistent Productivity Shock \\
$\varepsilon$ & $\varepsilon \in\left\{\varepsilon_{1}, \ldots, \varepsilon_{n}\right\}$ & Transitory Productivity Shock \\
\hline \hline
\end{tabular}

Notes: List of state variables of the economic model.

\subsubsection{Demographics}

Parents give birth to children when they are of age $j_{f}$. We denote the number of children a parental household has by $\xi(e, m)$, which differs by marital status and educational attainment of the parents. There is no survival risk and all households live until age $J$. Therefore the cohort size within each generation remains constant over time. We now describe in detail how life unfolds first for parents and then for children, as summarized in Figure 5.

\subsubsection{Life of the Parental Generation}

In the model, parental households start their economic life at age $j_{f}$ just before their children are born. Their initial characteristics include their exogenous marital status $m$, education level $e$, initial idiosyncratic productivity states $\eta$ and $\varepsilon$ and initial assets $a$. These initial states are exogenously given to the household, and drawn from the population distribution $\Phi(e, m, \eta, \varepsilon, a)$ which are estimated directly from the data, as described in the calibration section.

Parents then observe the innate ability (initial human capital) $h=h_{0}(e, m)$ of their children at child model age $j_{0}=0$ (real biological age 4), which depends on parental education $e$ and marital status $m$. Based on parental state variables $e, m, \eta, \varepsilon, a$ and the child's innate ability $h_{0}(e, m)$, parents first decide whether they will send their children to a public or a private school, $s \in$ $\{p u, p r\}$, from age $j_{s}>j_{0}$ (real biological age 6) of the child onward. If parents opt for private school, then throughout the schooling period they pay private school tuition $f(j, s=p r)>0$, 
Figure 5: Life-Cycle of Child and Parental Households

(a) Life-Cycle of Parental Households

\section{Initial Distribution \\ Children \\ Leave Household}

$\Phi(\mathrm{m}, \mathrm{e}, \mathrm{a})$
Pay inter-vivos transfers $b$

\section{Earnings while Working}

wage $w \in \eta \varepsilon$ until retirement

working time $\mathrm{I}(\mathrm{m})$ depends on marital status

$\epsilon=$ age and educ. specific wage profile

$\eta=$ persistent productivity shock, 2-state Markov

$\varepsilon=$ transitory productivity shock

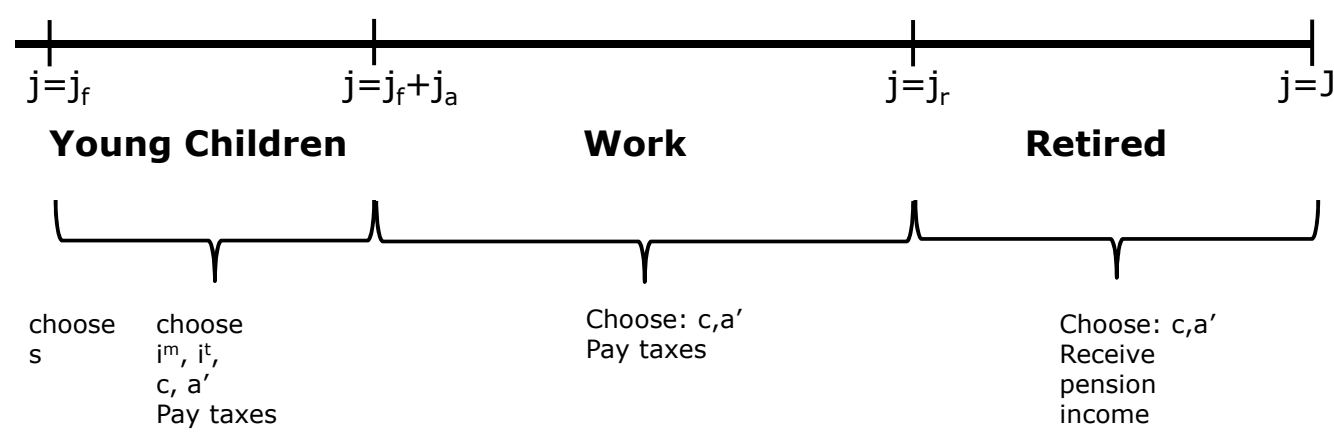

(b) Life-Cycle of Child Households

\begin{tabular}{|c|c|c|}
\hline Birth & $\begin{array}{l}\text { Higher Education? } \\
\text { At age } j_{a} \text { given } h\end{array}$ & $\begin{array}{l}\text { Earnings while Working } \\
\text { wage } w y(h) \in n \varepsilon \text { until retirement }\end{array}$ \\
\hline \multirow{5}{*}{$\begin{array}{l}\text { Innate } \\
\text { ability: } \\
\mathrm{h}= \\
\mathrm{h}_{0}\left(\mathrm{~m}_{\mathrm{p}}, \mathrm{e}_{\mathrm{p}}\right)\end{array}$} & i) parents pay inter-vivos & working time $\mathrm{I}(\mathrm{s})$ after completed education \\
\hline & ii) children make higher & \\
\hline & education decision, with & $Y(h)=$ fixed effect \\
\hline & $\begin{array}{l}\text { psychological costs } \\
p\left(s, e, h, e_{p}\right)\end{array}$ & $\begin{array}{l}\epsilon=\text { age and educ. specific wage profile } \\
\eta=\text { persistent productivity shock, } 2 \text {-state Markov } \\
\varepsilon=\text { transitory productivity shock }\end{array}$ \\
\hline & Choice: $\mathrm{e}=(\mathrm{no}, \mathrm{hs}, \mathrm{co})$ ? & \\
\hline
\end{tabular}

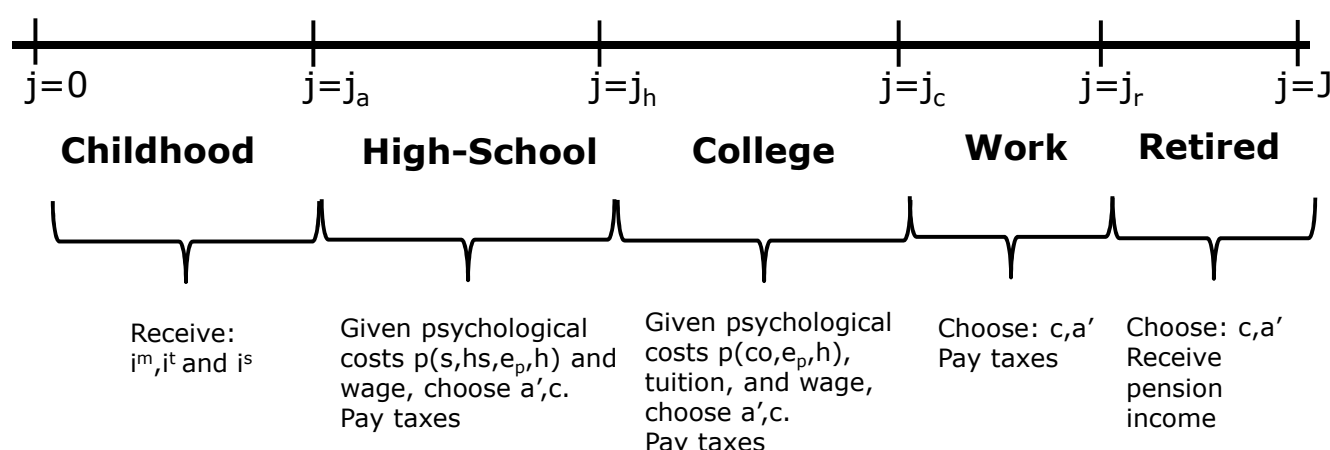


which depends on a child's age $j$ because we distinguish between tuition for primary and secondary education. ${ }^{9}$ Attendance in public schools is free, $f(j, s=p u)=0$.

Children live with their parents until child age $j_{a}$ (parental age $\left(j_{f}+j_{a}\right)$ ), at which point they leave the household to form their own independent household. During these years (parental ages $j \in\left\{j_{f}, \ldots, j_{f}+j_{a}\right\}$ ), parents invest resources $i^{m}$ and time $i^{t}$ into their children, which together with schooling $i^{s}(j)$ determines the evolution of a child's human capital. Conditional on school type (public or private), parents take age-dependent schooling inputs $i^{s}(j)$ as given. As a result of these choices, the human capital of a child during school ages evolves according to

$$
h^{\prime}=g\left(j, s, h, i\left(i^{m}, i^{t}, i^{s}(j)\right)\right)
$$

where $g$ is a function of the child's age $j$ (to reflect age differences in the relative importance of education inputs) as well as a function of the school type $s$ (to reflect potential productivity differences across the two school types), and depends positively on the three inputs (parental resources $i^{m}$, parental time $i^{t}$ and schooling input $\left.i^{s}(j)\right)$.

When children leave the household at parental age $j_{f}+j_{a}$, their parents may give them inter-vivos transfers $b \geq 0$. This is the final interaction between parents and children, after which the two households separate. Note that since children in high school continue their education for one period after they have left the parental household, parental transfers to those children who attend a private high school have to be at least as large as private school tuition, i.e., we impose the stricter constraint $b(\cdot, s=p r) \geq f\left(j_{a}, s=p r\right)$.

The remainder of parental life then unfolds as a standard consumption-saving life cycle model. Throughout their working ages, parental households spend an exogenous amount of time $\ell(m)>$ 0 on market work which differs by marital status. Labor productivity and thus individual wages are determined by an exogenous productivity profile $\epsilon(j, e, m)$ that depends on household age $j$, education $e$, marital status $m$, and is impacted by a persistent shock $\eta$ and a transitory shock $\varepsilon$. The persistent shock $\eta$ follows a first-order Markov chain with state space $\left\{\eta_{l}, \eta_{h}\right\}$, transition matrix $\pi\left(\eta^{\prime} \mid \eta\right)$ and initial distribution $\Pi$. The transitory shock can take values $\varepsilon \in\left\{\varepsilon_{1}, \varepsilon_{2}\right\}$ and is drawn from distribution $\psi(\varepsilon)$.

Current labor income of parents of age $j$, education $e$ and marital status $m$ and hit by shocks $(\eta, \varepsilon)$ is then given by

$$
y=w \cdot \epsilon(j, e, m) \cdot \eta \cdot \varepsilon \cdot \ell(m) .
$$

In addition to making human capital investment decisions for their children when these are present in the household, parents in each period make a standard consumption-saving choice,

\footnotetext{
${ }^{9}$ We also assume that at age $j_{0}$ (age 4 in real time) children go to kindergarten for free, $f(j=0, s)=0$.
} 
where household asset choices are subject to a potentially binding borrowing constraint $a^{\prime} \geq$ $-\underline{a}(j, e, m, p a)$, which will be parameterized such that the model replicates well household debt at the age at which households have children $j_{f}$. The borrowing limits decline linearly to zero over the life cycle towards the last period of work. Parents work until retirement at age $j_{r}$, at which point the start to receive per-period retirement benefits $b^{p}>0$ until the end of life at age $J$; these benefits are earnings-history-dependent.

Table 5 summarizes the choices of parents described thus far, and those of children, to which we turn next.

Table 5: Per Period Decision Variables

\begin{tabular}{lccc}
\hline \hline State Var. & Values & Decision Period & Interpretation \\
\hline$c$ & $c>0$ & $j \geq j_{a}$ & Consumption \\
$a^{\prime}$ & $a^{\prime} \geq-\underline{a}(j, e, m, k)$ & $j \geq j_{a}$ & Asset Accumulation \\
$s$ & $s \in\{p u, p r\}$ & $j=j_{f}$ & School Type \\
$i^{t}$ & $i^{t} \geq 0$ & $j \in\left\{j_{f}, \ldots, j_{f}+j_{a}-1\right\}$ & Time Investments \\
$i^{m}$ & $i^{m} \geq 0$ & $j \in\left\{j_{f}, \ldots, j_{f}+j_{a}-1\right\}$ & Monetary Investments \\
$b$ & $b \geq 0$ & $j=j_{f}+j_{a}$ & Monetary Inter-vivos Transfer \\
$e$ & $e \in\{n o, h i, c o\}$ & $j=j_{a}$ & (Higher) Education \\
\hline \hline
\end{tabular}

Notes: List of decision variables of the economic model.

\subsubsection{Life of the Children Generation}

Children born at age $j=0$ are economically inactive for the first $j_{a}-1$ periods of their life. After their parents have decided on the the type of school $s \in\{p u, p r\}$ a child's human capital during ages $j \in\left\{0, \ldots, j_{a}-1\right\}$ evolves as the outcome of parental investment decisions $\left(i^{m}, i^{t}\right)$ described above and schooling input $i^{s}(j)$. At the beginning of age $j_{a}$, and based on both the level of human capital as well as the financial transfer $b$ from their parents (which determines their initial wealth $a$ ), children make a discrete higher education decision $e \in\{n o, h s, c o\}$, where $e=n o$ stands in for the choice not to complete high school, hs for high school completion, and co for college completion, respectively. For simplicity, children are stand-in bachelor households through their entire life-cycle.

Acquiring a high school or college degree $e \in\{h s, c o\}$ comes at a utility cost (psychological cost) $p\left(s, e, e_{p}, h\right)$, which is decreasing in the child's acquired human capital $h$ and also depends on parental education $e_{p}$ as well as on whether the student attended private or public school, $s \in$ $\{p u, p r\}$. In addition, college education requires a monetary cost $\iota \geq 0$. Children may finance some of their college expenses by borrowing, subject to a credit limit given by $-\underline{a}(j, e, c h)$, which is zero for $e \in\{n o, h s\}$, i.e. for individuals not going to college. As was the case for parents, 
this limit decreases linearly with age and converges to zero at the age of retirement $j_{r}$, requiring the children generation to pay off their student loans prior to their retirement.

Youngsters who decide not to complete high school, $e=n o$, enter the labor market immediately at age $j_{a}$. Those who decide to complete high school, but not to attend college, do so at age $j_{h}>j_{a}$. While at high school, $\left\{j_{a}, \ldots, j_{h}-1\right\}$, they work part-time at wages of education group $e=n o$, and those children attending a private high-school also have to pay the school tuition $f(j, s=p r)>0$. Those youngsters who decide to attend college enter the labor market at $j_{c}>j_{h}$ and also work part-time at wages of education group $e=n o$ during their high-school and college years $\left\{j_{a}, j_{c}-1\right\}$.

When the children generation enters the labor market (either without a high-school diploma, with a high-school degree of with a college degree), the acquired human capital during the school years is mapped into an idiosyncratic permanent labor productivity state $\gamma(e, h)$, which is increasing in acquired human capital $h$ and also positively depends on education $e$ to reflect differential complementarities between education and human capital in the generation of earnings. When starting to work, children also draw the persistent productivity shock $\eta$, which follows the same first-order Markov chain as for the parental generation, and stochastic transitory productivity $\varepsilon \sim \psi(\varepsilon)$. Labor income of children during the working period is then given by

$$
w \cdot \gamma(e, h) \cdot \epsilon(j, e, s i) \cdot \eta \cdot \varepsilon \cdot \ell(s i)
$$

We restrict attention to the two generations directly impacted by the Covid-19 school crisis, and thus assume that the child generation does not have offspring of their own. As a consequence the remaining decision problem of the child generation, after labor market entry, constitutes a completely standard life-cycle consumption-saving problem.

\subsection{Recursive Formulation of the Decision Problems}

Our model is a partial equilibrium model where the only interaction of the decision problems comes in the period in which the children generation leaves the household. Furthermore, children do not make economic decisions prior to that period. We can therefore solve the entire model backward, starting from the retirement phase of the children generation. The details of those recursive problems not spelled out explicitly in the main text are contained in Appendix A.

\subsubsection{Children}

The children generation undergoes three distinct phases, first making the education decision, and then and living through a working phase and a retirement phase with which we begin. 
The Retirement Phase During the retirement phase, at ages $\left\{j_{r}, \ldots, J\right\}$, the children generation solve a standard consumption-saving $\left(c, a^{\prime}\right)$ maximization problem, facing a typical budget constraint of the form:

$$
c\left(1+\tau^{c}\right)+a^{\prime}=a\left(1+r\left(1-\tau^{k}\right)\right)+\operatorname{pen}\left(e, \eta_{j_{r}-1}, h\right)-T\left(\operatorname{pen}\left(e, \eta_{j_{r}-1}, h\right)\right)
$$

where pen $\left(e, \eta_{j_{r}-1}, h\right)$ is pension income, whose dependence on $\eta_{j_{r}-1}$ (the persistent income state in the period prior to retirement), education $e$ and human capital $h$ captures the progressive nature of the social security system in past earnings, which are in turn determined by $\left(e, \eta_{j_{r}-1}, h\right)$. The function $T(\cdot)$ represents a progressive labor income tax code, and capital and consumption are taxed at proportional rates $\left(\tau^{k}, \tau^{c}\right)$. The associated value function at the time of retirement is given by $V\left(j_{r}, e, \eta ; a\right)$ with $\eta=\eta_{j_{r}-1}$.

Working Life Let $V(j, e, \eta, \varepsilon ; a)$ denote the value function of a children household (assumed to be single) aged $j$ that has entered the labor market with education level $e$, human capital $h$ and has received stochastic income shocks $(\eta, \varepsilon)$. This value function is the result of a standard consumption-saving maximization problem, as for retired households, but with budget constraint now given by

$$
\begin{aligned}
c\left(1+\tau^{c}\right)+a^{\prime} & =a\left(1+r\left(1-\tau^{k}\right)\right)+y\left(1-\tau^{p}\right)-T\left(y\left(1-0.5 \tau^{p}\right)\right) \\
y & =w \gamma(e, h) \epsilon(e, j, s i) \eta \varepsilon \ell(s i)
\end{aligned}
$$

Here $\left(1-0.5 \tau^{p}\right) y$ is taxable labor income, with $\tau^{p}$ being the social security payroll tax. The argument of the tax function $T$ encodes that employer contributions to social security are not taxable income. In addition to the budget constraint, the household faces an age-, education, and generation-specific borrowing limit $a^{\prime} \geq-\underline{a}(j, e, c h)$.

The Higher Education Choice The key choice of the children generation impacted by the Covid-19 crisis and associated loss in schooling is the higher education decision this generation will make in the model right after the establishment of an independent household, and after having received inter-vivos transfers from their parents. 16-year-olds have three discrete choices $e \in\{n o, h s, c o\}$ : they can either decide to drop out of high school and enter the labor market directly at age 16 , or complete high school prior to labor market entry at age 18 , or third, go to and complete college at age 22 prior to labor market entry. To spell out this higher education decision problem, we first have to specify the values from each of these three discrete options. 
Dropping Out of High School Members of the children generation that made the decision to drop out of high school at model age $j_{a}$ (real age 16), i.e. chose $e=n o$, directly enter the labor market with permanent deterministic productivity $\gamma(e, h)$, then draw the persistent income shock $\eta \sim \Pi(\eta)$ (which then evolves according to the Markov transition matrix $\pi\left(\eta^{\prime} \mid \eta\right)$ ) and the transitory income shock $\varepsilon \sim \psi(\varepsilon)$. The expected value of entering the labor market as a high-school drop-out is then given by ${ }^{10}$

$$
V\left(j_{a}, e=n o, a, h\right)=\sum_{\eta} \Pi(\eta) \sum_{\varepsilon} \psi(\varepsilon) V\left(j_{a}, e=n o, \eta, \varepsilon, a, h\right)
$$

where $V(j, e, \eta, \varepsilon, a, h)$ is the lifetime utility of a worker of age $j$ with assets and human capital $(a, h)$ that has drawn productivity shocks $(\eta, \varepsilon)$, as defined in the previous paragraph.

Completing High School Youngsters that at age $j_{a}$ decide to complete high school but not attend college (i.e. choose $e=h s$ ) work part-time during high school at a deterministic wage and then enter the labor market two years later at $j=j_{a}+1$, when they draw stochastic labor productivity $\eta \sim \Pi(\eta), \varepsilon \sim \psi(\epsilon)$. In contrast to the $e=n o$ group, for children choosing $e=h i$ their school type $s$ is a relevant state variable because children in private high school have to pay the private school tuition $f(j, s=p r)$. Parental education $e_{p}$ is a state variable since the utility cost of completing high school $p\left(s, h s, e_{p}, h\right)$ depends on the eduction of their parents. Expected lifetime utility from high school completion is then given by

$$
\begin{aligned}
V\left(j_{a}, s, e=h s, e_{p}, a, h\right)=\max _{c, a^{\prime}}\left\{u(c)-v(\chi(h s) \ell(s i))-p\left(s, h s, e_{p}, h\right)+\right. \\
\left.\beta \sum_{\eta^{\prime}} \Pi\left(\eta^{\prime}\right) \sum_{\varepsilon^{\prime}} \psi\left(\varepsilon^{\prime}\right) V\left(j_{a}+1, e=h s, \eta^{\prime}, \varepsilon^{\prime}, a^{\prime}, h\right)\right\}
\end{aligned}
$$

subject to

$$
\begin{aligned}
a^{\prime}+c\left(1+\tau^{c}\right) & =a\left(1+r\left(1-\tau^{k}\right)\right)+y\left(1-\tau^{p}\right)-T\left(y\left(1-0.5 \tau^{p}\right)\right)-f(j, s) \\
y & =w \gamma(n o, h) \epsilon(n o, j, s i) \chi(h s) \ell(s i) \\
a^{\prime} & \geq 0 .
\end{aligned}
$$

That is, high-school students work for high-school drop-out wages $w \gamma(n o, h)$ for a fraction $\chi(h s)$ of their time $\ell(s i)$ and obtain period utility from consumption $u(c)$ and disutility from (exogenous) labor supply $v(\chi(h s) \ell(s i))$. The utility cost $p\left(s, h s, e_{p}, h\right)$ associated with attending high school is

\footnotetext{
${ }^{10}$ Since high-school drop-outs do not pay private school tuition any longer, nor face utility costs of attending school or college (which depends on the education of their parents), neither school type $s$ nor parental education $e_{p}$ is a state variable for high-school drop-outs.
} 
decreasing in the human capital $h$ previously acquired by the student. Children form expectations over their stochastic labor market productivity when they enter the labor market upon graduating at age $j_{a}+1$. Their remaining life (labor market and retirement phases) then unfold as described above.

Obtaining a College Degree Children who decide, at age $j_{a}$, to attend, and by assumption, to complete, college (i.e choose $e=c o$ ), during high school age $j_{a}$ solve the same problem as those who chose a high school education $(e=h s)$, with the difference that the continuation value differs at age $j_{a}+1$ (the youngster goes to college rather than entering the labor market). Thus the value of choosing, at age $j_{a}$, the college option, is given by

$$
\begin{aligned}
& V\left(j_{a}, s, e=c o, e_{p}, a, h\right)=\max _{c, a^{\prime}}\left\{u(c)-v(\chi(h s) \ell(s i))-p\left(s, h s, e_{p}, h\right)+\right. \\
&\left.\beta V\left(j_{a}+1, e=c o, e_{p}, a^{\prime}, h\right)\right\}
\end{aligned}
$$

where $V\left(j_{a}+1, e=c o, a^{\prime}, h\right)$ is expected lifetime utility at age $j_{a}+1$ (age 18 in real time) from entering college. The budget set is identical to that in equations (6). Note that this value function still depends on parental education $e_{p}$ because the utility cost from attending college $p\left(c o, e_{p}, h\right)$ will be, but no longer on high school type $s$.

Finally, during the two college periods students pay college tuition $\iota$ and work part-time at high-school wages. Furthermore, they can borrow up to a limit $\underline{a}(j, c o, c h)$ to pay for tuition. Thus their budget set is described by

$$
\begin{aligned}
a^{\prime}+c\left(1+\tau^{c}\right) & =a\left(1+r\left(1-\tau^{k}\right)\right)+y\left(1-\tau^{p}\right)-T\left(y\left(1-0.5 \tau^{p}\right)\right)-\iota \\
y & =w \gamma(h s, h) \epsilon(h s, j, s i) \chi(c o) \ell(s i) \\
a^{\prime} & \geq-\underline{a}(j, c o, c h) .
\end{aligned}
$$

The Bellman equation differs slightly between age $j_{a}+1$ and $j_{a}+2$ since at the first age students have two years (one model period) left in college, whereas at age $j_{a}+2$ their continuation value is determined by labor market entry as college graduate. Thus the corresponding Bellman equations are

$$
V\left(j_{a}+1, c o, e_{p}, a, h\right)=\max _{c, a^{\prime}}\left\{u(c)-v(\chi(c o) \ell(s i))-p\left(c o, e_{p}, h\right)+\beta V\left(j_{a}+2, c o, e_{p}, a^{\prime}, h\right)\right\}
$$


and

$$
\begin{aligned}
V\left(j_{a}+2, c o, e_{p}, a, h\right)=\max _{c, a^{\prime}}\left\{u(c)-v(\chi(c o) \ell(s i))-p\left(c o, e_{p}, h\right)+\right. \\
\left.\quad \beta \sum_{\eta^{\prime}} \Pi\left(\eta^{\prime}\right) \sum_{\varepsilon^{\prime}} \psi\left(\varepsilon^{\prime}\right) \cdot V\left(j_{a}+3, c o, \eta^{\prime}, \varepsilon^{\prime}, a^{\prime}, h\right)\right\} .
\end{aligned}
$$

which are both maximized subject to equations (8). Here, as before, $V\left(j_{a}+3, c o, \eta^{\prime}, \varepsilon^{\prime}, a^{\prime}, h\right)$ is expected utility lifetime from entering the labor market as a college graduate at age $j_{a}+3$ (age 22 in real time) with (human) capital $\left(a^{\prime}, h\right)$ and having drawn initial shocks $\left(\eta^{\prime}, \varepsilon^{\prime}\right)$.

The Education Decision At age $j_{a}$, based on their initial asset position $a$, their acquired human capital $h$, the type of school they attended $s$ and the education of their parents $e_{p}$ children make an education decision $e \in\{n o, h s, c o\}$. Above, we have spelled out the values $V\left(j_{a}, s, e, e_{p}, a, h\right)$ for these three choices. The choice is simply to choose the alternative that gives the highest expected lifetime utility, and the pre-education decision value function of children aged $j_{a}$ (which will enter parental lifetime utility through one-sided altruism) is given by:

$$
\begin{aligned}
& V\left(j_{a}, s, e_{p}, a, h\right)= \\
& \quad \max _{e \in\{n o, h s, c o\}}\left\{V\left(j_{a}, e=n o, a, h\right), V\left(j_{a}, s, e=h s, e_{p}, a, h\right), V\left(j_{a}, s, e=c o, e_{p}, a, h\right)\right\} .
\end{aligned}
$$

In the computational implementation, we additionally apply Extreme Value Type I (Gumbel) distributed taste shocks to smooth this discrete decision problem. ${ }^{11}$ Accordingly, youngsters choose the three education alternatives with state $\left(j_{a}, s, e_{p}, a, h\right)$-specific probabilities $\pi\left(j_{a}, s, e, e_{p}, a, h\right)$, for $e \in\{n o, h s, c o\}$.

\subsubsection{Parents}

Given the focus of the paper, we model parental households as becoming economically active at the beginning of age $j_{f}>j_{a}$ when they give birth to children. Since human capital formation of parents is completed at this stage, we normalize parental human capital to $h=1$ and let it be constant over the remainder of parental life. Children live with adult households until they form their own households and make decisions as described above. Household separation occurs at parental age $j_{f}+j_{a}$, after which the parental generation lives through a standard life cycle model whose recursive formulation is described in Appendix A.2. Let $V\left(j_{a}+j_{f}+1, e, m, \eta^{\prime}, \varepsilon^{\prime}, a^{\prime}\right)$ denote the expected lifetime utility (explicitly spelled out in the Appendix) from this life cycle of a parent

\footnotetext{
${ }^{11}$ Given this structure, the set of individuals exactly indifferent between two education choices is of measure zero and thus it is inconsequential how we break the indifference.
} 
household at the beginning of age $j_{a}+j_{f}+1$ with education and marital status $(e, m)$, stochastic productivity shocks $\left(\eta^{\prime}, \varepsilon^{\prime}\right)$ and assets $a^{\prime}$. Working backward in age, we now discuss the intervivos transfer decision when children leave the household, the child human capital investment decisions, and finally, the school choice (private or public school).

Inter-Vivos Transfers At parental age $j_{f}+j_{a}$ children leave the household, and at this age parents can make inter-vivos transfers $b$. These transfers immediately (that is, within the period) become assets of their children. The dynamic program of parents at this age then reads is

$$
\begin{aligned}
& V\left(j_{a}+j_{f}, s, e, m, \eta, a, h\right)=\max _{c, b, a^{\prime}}\left\{u\left(\frac{c}{1+\mathbf{1}_{m=m a} \zeta_{a}}\right)-v\left(\frac{\ell(m)}{1+\mathbf{1}_{m=m a}}\right)\right. \\
& \left.+\beta \sum_{\eta^{\prime}} \pi\left(\eta^{\prime} \mid \eta\right) \sum_{\varepsilon^{\prime}} \pi\left(\varepsilon^{\prime}\right) V\left(j_{a}+j_{f}+1, e, m, \eta^{\prime}, \varepsilon^{\prime} ; a^{\prime}\right)+\nu V\left(j_{a}, s, e_{p}, \frac{b}{1+r\left(1-\tau^{k}\right)}, h\right)\right\}
\end{aligned}
$$

subject to

$$
\begin{aligned}
a^{\prime}+c\left(1+\tau^{c}\right)+\xi(e, m) b & =a\left(1+r\left(1-\tau^{k}\right)\right)+y\left(1-\tau^{p}\right)-T\left(y\left(1-\tau^{p}\right)\right) \\
y & =w \epsilon(e, j, m) \eta \varepsilon \ell(m) \\
a^{\prime} & \geq \underline{a}\left(j_{a}+j_{f}, e, m, p a\right) .
\end{aligned}
$$

Here $V\left(j_{a}, s, e_{p}, \frac{b}{1+r\left(1-\tau^{k}\right)}, h\right)$ is the pre-education decision value function of their children defined in equation (9), and the parameter $\nu$ measures the intensity of altruism of parents towards their children. ${ }^{12}$ Note that the school type $s$ seizes to be a state variable in the value function of parents at age $j_{f}+j_{a}+1$ because children have left the household and thus pay the private school tuition (if they attend a private school) themselves. Also notice that private school fees are no longer present in the parental budget constraint because these fees are now paid by the children if they decide to continue with high school.

Investment Decision The value function of children in the previous dynamic program that parents solve at age $j_{f}+j_{a}$ includes their human capital $h$ since it determines both the higher education decision as well as future earnings of this generation directly. We now turn to the accumulation of this human capital when the children are of school age and reside with their

\footnotetext{
${ }^{12}$ Note that since assets in the value function enter the budget constraint as being multiplied by the gross, after-tax interest rate $1+r\left(1-\tau^{k}\right)$, and since inter-vivos transfers are received in the same period in which they are made and thus do not accrue interest, these transfers $b$ have to be divided by $1+r\left(1-\tau^{k}\right)$ on the right hand side of the Bellman equation above.
} 
parents (at parental ages $\left\{j_{f}, \ldots, j_{f}+j_{a}-1\right\}$ ). During these ages parents invest resources $i^{m}$ and time investments $i^{t}$ into each of their $\xi(e, m)$ children and pay private, child-age dependent per-child school tuition $f\left(j-f_{f}, p r\right)>0$ in case children attend private school. Parents derive utility from per capita consumption of its household members and suffer disutility from hours worked in the market and at home taking care of their children (rather than enjoying leisure). The dynamic program during this stage of the parental life cycle can then be written as

$$
\begin{aligned}
& V(j, s, e, m, \eta, \varepsilon, a, h)=\max _{c, i^{m}, i^{t}, a^{\prime}, h^{\prime}}\left\{u\left(\frac{c}{1+\zeta_{c} \xi(e, m)+\mathbf{1}_{m=m a} \zeta_{a}}\right)\right. \\
& \left.-v\left(\frac{\ell(m)+\kappa \cdot \xi(e, m) \cdot i^{t}}{1+\mathbf{1}_{m=m a}}\right)+\beta \sum_{\eta^{\prime}} \pi\left(\eta^{\prime} \mid \eta\right) \sum_{\varepsilon^{\prime}} \psi\left(\varepsilon^{\prime}\right) V\left(j, s, e, m, \eta^{\prime}, \varepsilon^{\prime} ; a^{\prime}, h^{\prime}\right)\right\}
\end{aligned}
$$

subject to

$$
\begin{aligned}
c\left(1+\tau^{c}\right)+a^{\prime}+\xi(e, m)\left(i^{m}+f\left(j-j_{f}, s\right)\right) & =a\left(1+r\left(1-\tau^{k}\right)\right)+y\left(1-\tau^{p}\right)-T\left(y\left(1-0.5 \tau^{p}\right)\right) \\
y & =w \epsilon(e, j, m) \eta \varepsilon \ell(m) \\
a^{\prime} & \geq-\underline{a}(j, e, m, p a) \\
h^{\prime} & =g\left(j-j_{f}, s, h, i\left(i^{m}, i^{t}, i^{s}\left(j-j_{f}\right)\right)\right)
\end{aligned}
$$

The parameter $\kappa$ is a weight on time spent with children, and reflects the possibility that reading to children carries a different disutility (or even positive utility) of time than work. Note that the sum of hours worked and time investment in children in the function $v(\cdot)$ is divided by the number of working household members.

Private Schooling Decision At the very start of the parental life cycle, at age $j_{f}$ and after observing the innate human capital $h=h_{0}(e, m)$ of their children (and after having observed their own transitory and persistent earnings shocks $(\eta, \varepsilon)$ ), parents decide on whether to send their children to a public or a private school. For computational tractability we assume that this decision is permanent and irreversible. The optimal choice of whether to send their children to private school depends on the initial characteristics of the parents $(e, m, a)$ (their education, martial status and financial wealth) and trades off the cost of private school tuition throughout the child's schooling years with higher productivity in the human capital production function and thus higher human capital (and associated higher chance of attending college) as well as 
ultimately, higher expected earnings of their children. The optimal choice of parents is given by ${ }^{13}$

$$
s= \begin{cases}p u & \text { if } V\left(j_{f}, s=p u, e, m, \eta, \varepsilon ; a, h_{0}\right) \geq V\left(j_{f}, s=p r, e, m, \eta, \varepsilon ; a, h_{0}\right) \\ p r & \text { otherwise. }\end{cases}
$$

This education choice $s$ then becomes a state variable in the parents' dynamic programs going forward, as described above.

\subsection{Government}

The government runs a pension system with a balanced budget. It also finances exogenous government spending, expressed as a share of aggregate output $G / Y$, and aggregate education spending on public schools (for pre-tertiary and tertiary education) through consumption taxes, capital income taxes and the progressive labor income tax system $T(y)$. In the initial pre-Covid19 scenario, the government budget clears by adjustment of the average labor income tax rate encoded in $T($.$) . In the thought experiment with school closures we hold fiscal policy constant,$ therefore implicitly assuming that the budget deficits or surpluses generated by a change in private behavior are absorbed by government debt which is serviced or repaid by future generations not explicitly modeled.

\subsection{The Covid-19 Thought Experiment}

We compute an initial stationary partial equilibrium with exogenous wages and returns prior to model period $t=0$. In period $t=0$, the COVID-19 shock unexpectedly hits, and from that point on unfolds deterministically. That is, factor prices and fiscal policies are fixed by our partial equilibrium assumption, and households, after the initial surprise, have perfect foresight with respect to aggregate economic conditions. The COVID-19 crisis impacts the economy through an education crisis: the government temporarily closes schools, represented in the model by a temporary reduction in school investment $i^{s}(j)$ into child human capital production. The reduction of $i^{s}(j)$ differs by type of school $s$ and age of the child $j$. We then trace out the impact of these temporary shocks on parental human capital inputs (both time and money) and intergenerational transfer decisions, as well as on the education choices, future earnings in the labor market, and ultimately, the distribution of welfare of the children generation, focusing specifically on the impact of the heterogeneity in the length of school closures by school type and

\footnotetext{
${ }^{13}$ As with the children's tertiary education decision, we assume that additionally parents are hit with Extreme Value Type I (Gumbel) distributed taste shocks to smooth this discrete decision problem and turns the discrete choice into a choice probability.
} 
the age of children. Since children in the model differ by age and the type of school they attend at the time of the shock (as well as in terms of parental characteristics), so will the long-run impact on educational attainment, future wages, and welfare.

\section{Calibration}

A subset of parameters is calibrated exogenously not using the model. These first stage parameters are summarized in Table 6 . The second stage parameters are those that are calibrated endogenously by matching moments in the data and are summarized in Table 7 . We next describe in detail our choice and sources of first stage parameters and the moments we match to calibrate the second stage parameters.

\subsection{Data}

In the first stage of calibration we use PSID data to estimate the deterministic age wage profiles and to construct the initial distribution of parents. Furthermore, we use NSLY79 data to estimate education-specific human capital gradients of the non-age related wage component. Finally, in the second stage of the calibration we use the Child Development Supplement (CDS) of the PSID, surveys I-III, to obtain empirical moments related to the child human capital and parental investments into children.

PSID. The initial distribution of parents by marital status, education, number of children and assets is constructed based on the four most recent PSID waves: 2011, 2013, 2015 and 2017. We use the PSID family files and keep only parents in the sample (i.e., only observations where children are present in the household). We keep only observations with positive hours and labor income of the household head. This leaves us with 7591 observations. Labor earnings and wealth are inflated to 2010 dollars using the CPI . Deterministic age wage profiles are estimated using a PSID sample from 1967 to $2013^{15}$ based on observations from both households with and without children.

NLSY79. We use the NLSY79 dataset provided in the replication files of Abbott et al. (2019). Following their approach, we approximate adult human capital by the test scores taken from the Armed Forces Qualification Test AFQT89.

\footnotetext{
${ }^{15}$ We thank Chris Busch for helping us with the data.
} 
Table 6: First Stage Calibration Parameters

\begin{tabular}{|c|c|c|c|}
\hline Parameter & Interpretation & Value & Source (data/lit) \\
\hline \multicolumn{4}{|c|}{ Population } \\
\hline$j=0$ & Age at economic birth (age 4) & 0 & \\
\hline$j_{a}$ & Age at beginning of econ life (age 16) & 6 & \\
\hline$j_{h}$ & Age at finishing HS (age 18) & 7 & \\
\hline$j_{c}$ & Age at finishing CL (age 22) & 9 & \\
\hline$j_{f}$ & Fertility Age (age 32) & 14 & \\
\hline$j_{r}$ & Retirement Age (age 66) & 31 & \\
\hline$J$ & Max. Lifetime (age 80) & 38 & \\
\hline$\xi(e, m)$ & Fertility rates & see main text & PSID 2011-2017 \\
\hline$\Phi\left(j_{f}, e, m\right)$ & $\begin{array}{l}\text { Distribution of parents by martial status and } \\
\text { education, age } j_{f}\end{array}$ & see main text & PSID 2011-2017 \\
\hline \multicolumn{4}{|c|}{ Preferences } \\
\hline$\theta$ & Relative risk aversion parameter & 1 & \\
\hline$\varphi$ & Curvature of labor disutility & 0.5 & \\
\hline \multicolumn{4}{|c|}{ Labor Productivity } \\
\hline$\{\epsilon(j, e, m)\}$ & Age Profile & see main text & PSID 1968-2012 \\
\hline$\left[\varepsilon_{l}, \varepsilon_{h}\right]$ & Realizations of Transitory Shock & {$[0.881,1.119]$} & PSID 1968-2012 \\
\hline$\left[\eta_{l}, \eta_{h}\right]$ & States of Markov process & {$[0.8226,1.1774]$} & PSID 1968-2012 \\
\hline$\pi_{h l}$ & Transition probability of Markov process & 0.0431 & PSID 1968-2012 \\
\hline$\chi^{e}$ & $\begin{array}{l}\text { Hours worked for students, as a fraction of full } \\
\text { time (HS and } \mathrm{CL})\end{array}$ & $\{0.2,0.5\}$ & see main text \\
\hline$\gamma(e, h)$ & Ability gradient of earnings & see main text & NLSY79 \\
\hline \multicolumn{4}{|c|}{ Endowments } \\
\hline$r$ & (Annual) interest rate & $4.0 \%$ & Siegel (2002) \\
\hline$l(m)$ & $\begin{array}{l}\text { Average hours worked by marital status (an- } \\
\text { nual) }\end{array}$ & $\{1868,3810\}$ & PSID 2011-2017 \\
\hline$\Phi\left(a \mid j_{f}, e, m\right)$ & $\begin{array}{l}\text { Asset distr-n of parents by martial status and } \\
\text { education, age } j_{f}\end{array}$ & see main text & PSID 2011-2017 \\
\hline$\underline{\mathrm{a}}\left(j_{f}, e, m, p a\right)$ & Borrowing limit for parents at age $j_{f}$ & see main text & PSID 2011-2017 \\
\hline$r p(m=s i, e, p a)$ & $\begin{array}{l}\text { Education-specific repayment amount for par- } \\
\text { ents: singles }\end{array}$ & see section 5.5 .4 & $\{0.006,0.083,0.151\}$ \\
\hline$r p(m=m a, e, p a)$ & $\begin{array}{l}\text { Education-specific repayment amount for par- } \\
\text { ents: couples }\end{array}$ & see section 5.5 .4 & $\{0.048,0.129,0.110\}$ \\
\hline \multicolumn{4}{|c|}{ Ability/Human Capital and Education } \\
\hline$f(j<4, s=p r)$ & Private school tuition (primary) & $3294 \$$ & PSID CDS I-III \\
\hline$f(j \geq 4, s=p r)$ & Private school tuition (secondary) & $6588 \$$ & PSID CDS I-III \\
\hline$\iota$ & $\begin{array}{l}\text { College tuition costs (annual, net of grants and } \\
\text { subsidies) }\end{array}$ & $14756 \$$ & Krueger and Ludwig (2016) \\
\hline$\underline{\mathrm{a}}\left(j \in\left[j_{h}, j_{c}-1\right], c o, c h\right)$ & College borrowing limit & $45000 \$$ & Krueger and Ludwig (2016) \\
\hline$r p(c h)$ & $\begin{array}{l}\text { Repayment amount for children who choose } \\
\text { college }\end{array}$ & 0.049 & see section 5.8 \\
\hline$\sigma^{h}$ & $\begin{array}{l}\text { Elast of subst b/w human capital and CES inv. } \\
\text { aggr. }\end{array}$ & 1 & Cunha et al. (2010) \\
\hline$\sigma^{g}$ & $\begin{array}{l}\text { Elast of subst b/w public inv. and CES aggr. of } \\
\text { private inv. }\end{array}$ & 2.43 & Kotera and Seshadri (2017) \\
\hline$\sigma^{m}$ & Elast of subst b/w monetary and time inv. & 1 & Lee and Seshadri (2019) \\
\hline$\kappa_{3}^{m}$ & $\begin{array}{l}\text { CES share parameter of monetary and time inv. } \\
\text { (age bin 6-8) }\end{array}$ & 0.5 & normalization \\
\hline $\begin{array}{l}\kappa_{j}^{s}=\bar{\kappa}^{s}, j>0, s \in \\
\{p r, p u\}\end{array}$ & Share of government input for ages 6 and older & 0.676 & Kotera and Seshadri (2017) \\
\hline$\Phi\left(h(j=0) \mid e_{p}, y_{p}, a_{p}\right)$ & $\begin{array}{l}\text { Innate ability dist-n of children by parental } \\
\text { char-s }\end{array}$ & see main text & PSID CDS I \\
\hline$\underline{h}_{0}$ & $\begin{array}{l}\text { Normalization parameter of initial dist-n of ini- } \\
\text { tial ability }\end{array}$ & 0.1248 & PSID CDS I-III \\
\hline \multicolumn{4}{|c|}{ Government policy } \\
\hline$i_{j}^{s}$ & Public pre-college education spending by age & $6,299 \${ }^{14}$ & UNESCO (1999-2005) \\
\hline$\tau_{c}$ & Consumption Tax Rate & $5.0 \%$ & legislation \\
\hline$\tilde{\tau}_{k}$ & Capital Income Tax Rate & $20 \%$ & legislation \\
\hline$\tau^{p}$ & Soc Sec Payroll Tax & $12.4 \%$ & legislation \\
\hline$G / Y$ & Government consumption to GDP & $13.8 \%$ & current value \\
\hline
\end{tabular}

Notes: First stage parameters calibrated exogenously by reference to other studies and data. 


\section{Table 7: Second Stage Calibration Parameters}

\begin{tabular}{|c|c|c|}
\hline Parameter & Interpretation & Value \\
\hline \multicolumn{3}{|c|}{ Preferences } \\
\hline$\beta$ & Time discount rate (target: asset to income ratio, age 25-60) & 0.9773 \\
\hline$\nu$ & Altruism parameter (target: average IVT transfer per child) & 0.7755 \\
\hline \multicolumn{3}{|c|}{ Labor Productivity } \\
\hline$\rho_{0}(e)$ & Normalization parameter (target: $\mathbb{E}[\gamma(h \mid e)]=1$ ) & {$[0.2965,0.0497,-0.2514]$} \\
\hline \multicolumn{3}{|c|}{ Human Capital and Education } \\
\hline$\kappa$ & Utility weight on time inv. (target: average time inv.) & 1.1024 \\
\hline$\alpha_{0}^{\kappa^{h}}$ & Slope parameter of $\ln \left(\frac{1-\overline{\kappa^{h}(j)}}{\kappa^{h}(j)}\right)$ (target: average monetary inv.) & -0.3988 \\
\hline$\left\{\alpha_{1}^{\kappa^{h}} \alpha_{2}^{\kappa^{h}}\right\}$ & Age-dependency of $\kappa^{h}$ (target: slope of time inv.) & $\{0.2465,0.0020\}$ \\
\hline$\alpha_{1}^{\kappa^{m}}$ & Age-dependency of $\kappa^{m} \overline{\text { (target: slope of money inv.) }}$ & 0.1493 \\
\hline$\kappa_{0}^{g}$ & $\begin{array}{l}\text { Share of government input for age bin 4-6 (target: average time inv. } \\
\text { age bin 4-6) }\end{array}$ & 0.5554 \\
\hline$B^{s}$ & Productivity parameter for $s=p r$ (target: fraction of group $s=p r$ ) & 1.5103 \\
\hline $\bar{A}$ & Investment scale parameter (target: average HK at age $j_{a}$ ) & 1.1906 \\
\hline$\tilde{A}$ & $\begin{array}{l}\text { Investment scale parameter for } e=h s, j=j_{a} \text { (target: average HK } \\
\left.\text { at age } j_{a+1}\right)\end{array}$ & 1.0657 \\
\hline$\phi$ & utility costs $e=h s$ (target: fraction of group $e=h s$ ) & -2.2373 \\
\hline $\begin{array}{l}\vartheta\left(s=p r, e_{p}=n o\right)= \\
\vartheta\left(s=p r, e_{p}=h s\right)\end{array}$ & $\begin{array}{l}\text { utility cost shifter } s=p r, e^{p}=n o \wedge e^{p}=h s \text { (target: conditional } \\
\text { fraction of group } s=p r \text { ) }\end{array}$ & 0.6588 \\
\hline $\begin{array}{l}\tilde{\varrho}\left(e_{p}=n o\right)=\tilde{\varrho}\left(e_{p}=\right. \\
h s)\end{array}$ & $\begin{array}{l}\text { utility costs } e=c o, e^{p}=n o \wedge e^{p}=h s \text { (target: fraction of group } \\
e=c o \text { ) }\end{array}$ & -0.9782 \\
\hline$\tilde{\varrho}\left(e_{p}=c o\right)$ & $\begin{array}{l}\text { utility costs } e=c o, e_{p}=c o \text { (target: conditional fraction of group } \\
e=c o \text { ) }\end{array}$ & -1.0493 \\
\hline \multicolumn{3}{|c|}{ Government policy } \\
\hline$\lambda$ & Level parameter of HSV tax function (balance gvt budget) & 0.8933 \\
\hline$\rho^{p}$ & Pension replacement rate (balance socsec budget) & 0.1893 \\
\hline
\end{tabular}

Notes: Second stage parameters calibrated endogenously by targeting selected data moments. 
PSID CDS. To obtain child related statistics by parental characteristics, we merge the CDS data files with the PSID family files of the respective waves. As children of married couples, we consider children for whom both caregivers correspond to the household head and the spouse in a PSID household, ${ }^{16}$ and for whom at least one of the caregivers is the biological parent. This leaves us with 4393 observations (2419 children) for the three waves of the survey. All children for whom the reported school type is private (354 observations) are classified as going to private schools-including those for whom parents report zero expenses on schooling fees ${ }^{17}$. The average schooling fee used as an exogenous input in the model is computed based on reported average expenses on schooling fees for children attending private schools. All descriptive statistics are computed using cross-sectional sample weights provided in the survey.

\subsection{Age Brackets}

The model is calibrated at a biannual frequency. We initialize the parental economic life-cycle when their children are of age 4 , which is model age $j=0$. The reason for this initialization age is the calibration of the initial human capital endowment $h(j=0)$, which is informed by data on test score measures at child biological ages 3 to 5 , as described below. Thus, children are irrelevant to the economic model for the first 3 years of their biological lives. Parental age at the economic "birth" of children is $j_{f}=14$, which we also refer to as "fertility" age. This corresponds to a biological age of 32 , when children are of biological age $4{ }^{18}$ Children make the higher eduction decision at biological age 16 , model age $j_{a}=6$. Children who complete high school stay in school for one additional model period, thus high school is completed at $j_{h}=7$. Children who attend college stay in college for two model periods, thus college is completed at $j_{c}=9$. Retirement is at the exogenous age $j_{r}=31$, corresponding to biological age 66 . Households live at most with certainty until age $J=38$, biological age 80 .

\subsection{Prices}

We normalize wages to $w=1$ and directly parameterize the income process. The interest rate is set to an annual rate of $4 \%$ based on Siegel (2002).

\footnotetext{
${ }^{16}$ In case of singles, only the household head is the primary caregiver.

${ }^{17}$ These observations can be either due to misreporting or represent those children who receive full scholarship.

${ }^{18}$ Thus, children are biologically born at parental age 28.
} 


\subsection{Preferences}

The per period subutility function $u(x)$ is of the standard iso-elastic power form

$$
u(x)=\frac{1}{1-\theta}\left(x^{1-\theta}-1\right) .
$$

We set $\theta=1$ (logarithmic utility), and consequently child and adult equivalence scale parameters are irrelevant for the problem. In the parental household's problem, the per period subutility function $v(x)$ is

$$
v(x)=x^{1+\frac{1}{\varphi}}
$$

so that if $x=\ell$, parameter $\varphi$ can be interpreted as a Frisch elasticity of labor supply. In our model of exogenous labor supply this interpretation of course seizes to be relevant, but it provides us with a direct way of calibrating the power term of the utility function. We set $\varphi=0.5$ based on standard estimates of the Frisch elasticity.

When children live in the parental household, we have $x=\frac{\ell(m)+\kappa \cdot \xi(e, m) \cdot i^{t}}{1+1_{m=m a}} . \ell(m)$ are hours worked by marital status, which we estimate from the data, giving annual hours of $\ell(s i)=1868$ and $\ell(m a)=3810$. The time cost parameter $\kappa$ is calibrated to match average time investments by parents into the education of children, giving $\kappa=1.10$ (with further details described below as part of the calibration of the human capital technology).

When children attend high school or college, they experience utility costs for $e \in\{h s, c o\}$ according to the cost function

$$
p\left(s, e, e_{p} ; h\right)=\phi\left(1+\varrho\left(e_{p}\right) \mathbf{1}_{j \in\left[j_{h}, j_{c}-1\right]} \mathbf{1}_{e=c o}\right)+\frac{1}{h}-\vartheta\left(s, e_{p}\right)
$$

Utility costs of obtaining a high-school degree are equal to $\phi+\frac{1}{h}-\vartheta\left(s, e_{p}\right)$ and are thus monotonically decreasing and convex in the acquired human capital $h$ and are shifted down by the school specific term $\vartheta\left(s, e_{p}\right)$, which reflects private benefits from private school attendance. Utility costs for obtaining a college degree depend on parental education and are equal to, $\tilde{\varrho}\left(e_{p}\right)+\frac{1}{h} \equiv \phi\left(1+\varrho\left(e_{p}\right)\right)+\frac{1}{h}$.

We normalize the benefit parameter of attending a private school to zero for parents with a college degree, $\vartheta\left(s=p r, e_{p}=c o\right)=0$, and further restrict $\vartheta\left(s=p r, e_{p}=n o\right)=\vartheta\left(s=p r, e_{p}=\right.$ $h s$ ) which we calibrate to match the conditional share of children in private school for both parental education groups of $9.71 \%$. This gives $\vartheta\left(s=p r, e_{p}=n o\right)=\vartheta\left(s=p r, e_{p}=h s\right)=0.66$. The remaining parameters of the cost function are calibrated to match education shares in the data for the three groups $e \in\{n o, h s, c o\}$. We measure these shares for adults older than age 22-which 
is the labor market entry age of all education groups in the model-and younger than age 38 based on the PSID waves 2011, 2013, 2015 and $2017 .{ }^{19}$ Parameter $\phi$ is calibrated to match the fraction of children without a high school degree of $12.16 \%$, giving $\phi=-2.24$. With regard to the additional utility costs during the college period we restrict $\tilde{\varrho}(n o)=\tilde{\varrho}(h s)$ and calibrate it to match the fraction of children with a college degree of $33.21 \%$ giving $\tilde{\varrho}(n o)=\tilde{\varrho}(h s)=-0.98$. Finally, parameter $\tilde{\varrho}\left(e_{p}=c o\right)$ is calibrated to match the fraction of children in college conditional on parents having a college degree of $63.3 \%$, cf. Krueger and Ludwig (2016), giving $\tilde{\varrho}(c o)=$ -1.05 .

Households discount utility at rate $\beta$. We follow Busch and Ludwig (2020) and calibrate it to match the assets to income ratio in the PSID for ages 25 to 60 giving an annual discount factor of $\beta=0.98$.

Utility of future generations is additionally discounted at rate $\nu$. Parameter $\nu$ is chosen so that average per child inter-vivos transfer is ca. $61,200 \$$, as implied by the Rosters and Transfers supplement to the PSID (based on monetary transfers from parents to children until age 26, see Daruich (2020)). This gives $\nu=0.78$.

\subsection{Initial Distribution of Parents}

For the initial distributions of parents at the fertility age, we restrict the sample to parents aged 25-35, leaving us with 3,024 observations. ${ }^{20}$

\subsubsection{Marital Status}

Marital status is measured by the legal status of parents. This gives a share of singles of $51.7 \%$ and a share of married households of $48.3 \%$.

\subsubsection{Education Categories}

We group the data by years of education of household heads older than age 22. Less than high school, $e=n o$, is for less than 12 years of formal education. High school completion (but no college) is for more than 12 but less than 16 years of education. College is at least 16 years of education. The population shares of parents in the three education categories by their marital status are summarized in Table $8 .{ }^{21}$

\footnotetext{
${ }^{19}$ Observe that we do not impose that children have the same education shares as parents.

${ }^{20}$ For education, which is not changing much with age, we keep parents aged 22 or above.

${ }^{21}$ The educational distribution is consistent with many other studies based on the PSID, cf., e.g., Heathcote et al. (2010).
} 
Table 8: Fraction of Households by Education for each Marital Status

\begin{tabular}{lcc}
\hline \hline Education $e /$ Marital Status $m$ & $s i$ & $m a$ \\
\hline$n o$ & 0.2194 & 0.1621 \\
$h s$ & 0.6064 & 0.5577 \\
$c o$ & 0.1742 & 0.2802 \\
\hline \hline
\end{tabular}

Notes: Fraction with education $e \in\{n o, h s, c o\}$ by marital status.

\subsubsection{Demographics}

The number of children by marital status and education of parents $\xi(e, m)$ is computed as the average number of children living in households with household heads aged 25-35. It is summarized in Table 9.

Table 9: Number of Children by Marital Status and Education

\begin{tabular}{lcc}
\hline \hline Education $e /$ Marital Status $m$ & $s i$ & $m a$ \\
\hline$n o$ & 2.36 & 2.33 \\
$h s$ & 1.86 & 2.15 \\
$c o$ & 1.77 & 1.96 \\
\hline \hline
\end{tabular}

Notes: Number of children by marital status and education.

\subsubsection{Assets}

Conditional on the initial distribution of parents by marital status and education, we measure the distribution of assets according to asset quintiles, which gives the initial distribution $\Phi(a \mid$ $\left.j_{f}, e, m\right)$. We set the borrowing constraint of parents as follows. First, we calculate average assets (debt) of the lowest asset quintile at age $j_{f}$ from the data and set it equal to a $\left(j_{f}, e, m, p a\right)$, the initial debt of parents in the lowest asset quintile in the model. The result is summarized in Table 10.

For all ages $j>j_{f}$ we then compute the borrowing limit recursively as:

$$
\underline{\mathrm{a}}(j, e, m, p a)=\underline{\mathrm{a}}(j-1, e, m, p a)(1+r)-r p(e, m, p a)
$$

where $r p(e, m, p a)$ is chosen such that the terminal condition $\underline{\mathrm{a}}\left(j_{r}, e, m, p a\right)=0$ is met. 
Table 10: Lower Asset Limit by Marital Status and Education

\begin{tabular}{lccc}
\hline \hline Education $e$ & Marital Status $m$ & $s i$ & $m a$ \\
\hline$n o$ & $-2,380$ & $-18,931$ \\
$h s$ & $-33,065$ & $-51,332$ \\
$c o$ & $-60,037$ & $-43,629$ \\
\hline \hline
\end{tabular}

Notes: Lower asset limit for parents at model age $j_{f}$, by marital status and education, expressed in 2010 dollars.

\subsubsection{Income}

We draw initial income shocks assuming independence of the asset position according to the stationary invariant distribution of the 2-state Markov process, thus $\Pi\left(\eta_{h}\right)=0.5$.

\subsection{Productivity}

We use PSID data to regress by education of the household head log wages measured at the household level on a cubic in age of the household head, time dummies, family size, a dummy for marital status, and person fixed effects. Predicting the age polynomial (and shifting it by marital status) gives our estimates of $\epsilon(e, m, j)$. We next compute log residuals and estimate moments of the earnings process by GMM and pool those across education categories and marital status. ${ }^{22}$ We assume a standard process of the log residuals according to a permanent and transitory shock specification, i.e., we decompose log residual wages $\ln \left(\mathrm{y}_{t}\right)$ as

$$
\begin{aligned}
& \ln \left(\mathrm{y}_{t}\right)=\ln \left(\mathrm{z}_{\mathrm{t}}\right)+\ln \left(\varepsilon_{t}\right) \\
& \ln \left(\mathrm{z}_{\mathrm{t}}\right)=\rho \ln \left(\mathrm{z}_{\mathrm{t}-1}\right)+\ln \left(\nu_{t}\right)
\end{aligned}
$$

where $\varepsilon_{t} \sim_{i . i . d} \mathcal{D}_{\varepsilon}\left(0, \sigma_{\varepsilon}^{2}\right), \nu_{t} \sim_{i . i . d} \mathcal{D}_{\nu}\left(0, \sigma_{\nu}^{2}\right)$ for density functions $\mathcal{D}$, and estimate this process pooled across education and marital status. To approximate the persistent component in our model, we translate it into a 2-state Markov process targeting the conditional variance of $\mathrm{z}_{\mathrm{t}}$, conditional on $\mathrm{z}_{\mathrm{t}-2},\left(1+\rho^{2}\right) \sigma_{\nu}^{2}$ (accounting for the two year frequency of the model). The transitory component is in turn approximated in the model by two realizations with equal probability with the spread chosen to match the respective variance $\sigma_{\varepsilon}^{2}$. The estimates and the moments of the approximation are reported in Table 11 .

We set the fraction of time working during high school to $\chi(h s)=0.2$, which can be interpreted as a maximum time of work of one day of a regular work week. In college, students may work for longer hours and we accordingly set $\chi(c o)=0.5$.

\footnotetext{
${ }^{22}$ We thank Zhao Jin for sharing her code with us.
} 
Table 11: Stochastic Wage Process

\begin{tabular}{|c|c|c|c|c|c|c|}
\hline & \multicolumn{3}{|c|}{ Estimates } & \multicolumn{2}{|c|}{ Markov Chain } & Transitory Shock \\
\hline Parameter & $\rho$ & $\sigma_{\nu}^{2}$ & $\sigma_{\varepsilon}^{2}$ & $\pi_{h h}=\pi_{l l}$ & {$\left[\eta_{l}, \eta_{h}\right]$} & {$\left[\varepsilon_{l}, \varepsilon_{h}\right]$} \\
\hline Estimate & 0.9559 & 0.0168 & 0.0566 & 0.9569 & {$[0.8226,1.1774]$} & {$[0.881,1.119]$} \\
\hline
\end{tabular}

Notes: Estimated moments of residual log wage process.

The mapping of acquired human capital into earnings according to $\gamma(e, h)$ is based on Abbott et al. (2019). We use their data-the NLSY79, which includes both wages and test scores $z$ of the Armed Forces Qualification Test (AFQT) — to measure residual wages $\omega(e)$ of education group $e$ (after controlling for an education specific age polynomial) and run the regression

$$
\ln (\omega(e))=\rho_{1}(e) \cdot \ln \left(\frac{z}{\bar{z}}\right)+v(e)
$$

where $v(e)$ is an education group specific error term and $\bar{z}$ are average test scores. We denote the education group specific coefficient estimate by $\hat{\rho}_{1}(e)$, see Table 12 . The estimated ability gradient is increasing in education reflecting complementarity between ability and education. In the model, we correspondingly let

$$
\ln (\gamma(e, h))=\rho_{0}(e)+\hat{\rho}_{1}(e) \cdot \ln \left(\frac{h}{\bar{h}}\right)
$$

where $\bar{h}$ is average acquired human capital at $j=j_{a}$ (biological age 16) and $\rho_{0}(e)$ is an education group e specific normalization parameter, chosen such that $\mathbb{E}[\gamma(h \mid e)]=1$ for all $e$. The normalization-which gives $\rho_{0}(e)=0.30,0.05,-0.25$, for $e \in\{n o, h s, c o\}$, respectively-implies that the average education premia are all reflected in $\epsilon(e, j, m a)$, which in turn are directly estimated on PSID data.

Table 12: Ability Gradient by Education Level

\begin{tabular}{lc}
\hline \hline Education Level & Ability Gradient \\
\hline HS- & $0.351(0.0407)$ \\
(HS \& CL-) & $0.564(0.0233)$ \\
$(\mathrm{CL} \& \mathrm{CL}+)$ & $0.793(0.0731)$ \\
\hline \hline
\end{tabular}

Notes: Estimated ability gradient $\hat{\rho}_{1}(e)$, using NLSY79 as provided in replication files for Abbott et al. (2019). Standard errors in parentheses. 


\subsection{Human Capital Production Function}

At birth at age $j=0$, the innate ability (initial human capital) $h=h_{0}$ of children is determined, conditional on the distribution of parents by parental characteristics $e_{p}, m_{p}$, by the function $h_{0}\left(e_{p}, m_{p}\right)$. We calibrate the distribution from the Letter Word test score distribution in the PSID Child Development Supplement (CDS) surveys I-III, and match it to parental characteristics by merging the survey waves with the PSID. Table 13 reports the joint distribution of average test scores of the children by parental education and marital status. We use this test score distribution as a proxy for the initial human capital distribution of children conditional on parental education and marital status. ${ }^{23}$ We base the calibration of the initial ability distribution of children on this data by drawing six different types of children depending on the combination of marital status (2) and parental education (3). Children's initial human capital is normalized as the test score of that $m_{p}, e_{p}$-group relative to the average test score. We further scale the resulting number by the calibration parameter $\bar{h}_{0}$ and, thus, initial human capital of the children is a multiple of $\bar{h}_{0}$. Parameter $\bar{h}_{0}$ is calibrated exogenously to match the ratio of mean test scores at ages 3-5 to mean test scores at ages $16-17$, which gives $\bar{h}_{0}=0.125$. Initial abilities relative to average abilities and the corresponding multiples of $\bar{h}_{0}$ for the six types are contained in Table 13.

Table 13: Initial Ability by Parental Education

\begin{tabular}{lcc}
\hline \hline Marital Status and Educ of HH Head & Avg. Score & Fraction of $h_{0}$ \\
\hline Single Low & 35 & 0.843 \\
Single Medium & 38 & 0.906 \\
Single High & 46 & 1.107 \\
Married Low & 39 & 0.945 \\
Married Medium & 41 & 0.984 \\
Married High & 45 & 1.085 \\
\hline \hline
\end{tabular}

Notes: Estimated initial ability of children as measured by the letter word test in the Child Development Supplement Surveys 1-3 (years 1997, 2002, 2007) of the PSID.

At ages $j_{0}, \ldots, j_{a}-1$ children receive parents' education investments through money and time $i^{m}(j), i^{t}(j)$ and school input $i^{s}(j)$. Education investments of the respective education institution $s \in\{p u, p r\}$ are certain, known by parents, and equal across children. In the baseline pre-Covid-19 scenario we normalize the education input in both institutions to 1 unit of time, thus $i^{s}(j)=1$ for both $s$ and all $j$. In private school one unit of time leads to a higher productivity than in public schools which is reflected in a productivity parameter $B^{s}$. Specifically,

\footnotetext{
${ }^{23}$ Importantly, by correlating the test score distribution with these parental characteristics, we do not pose a causal link between parental education and children's characteristics. The test scores just give us a convenient way to proxy the initial joint distribution.
} 
we normalize $B^{s}=1$, for $s=p u$ and calibrate $B^{s}>1$, for $s=p r$ endogenously to match the average fraction of parents with children in private schools of $11.24 \%$ observed in the data. This gives $B^{s}=1.51$ for $s=p r$. Given these inputs, human capital is acquired in a multi-layer human capital production function

$$
\begin{aligned}
h^{\prime}(j) & =\left(\kappa^{h}(j) h^{1-\frac{1}{\sigma^{h}}}+\left(1-\kappa^{h}(j)\right) i(j)^{1-\frac{1}{\sigma^{h}}}\right)^{\frac{1}{1-\frac{1}{\sigma^{h}}}} \\
i(j) & =\bar{A}\left(\kappa^{s}(j)\left(\mathbf{1}_{j \geq j e} B^{s} i^{s}(j)\right)^{1-\frac{1}{\sigma^{s}}}+\left(1-\kappa^{s}(j)\right)\left(\frac{i^{p}(j)}{\bar{i}^{p}}\right)^{1-\frac{1}{\sigma^{e}}}\right)^{\frac{1}{1-\frac{1}{\sigma^{s}}}} \\
i^{p}(j) & =\left(\kappa^{m}(j)\left(\frac{i^{m}(j)}{\bar{i}^{m, d}}\right)^{1-\frac{1}{\sigma^{m}}}+\left(1-\kappa^{m}(j)\right)\left(\frac{i^{t}(j)}{\bar{i}^{t, d}}\right)^{1-\frac{1}{\sigma^{m}}}\right)^{\frac{1}{1-\frac{1}{\sigma^{m}}}}
\end{aligned}
$$

which partially features age dependent parameters for calibration purposes. We divide the endogenous age dependent per child monetary and time investments by the parents $i^{m}(j), i^{t}(j)$, as well as the CES aggregate of these (normalized) investments, $i^{p}(j)$, by their respective unconditional means through which we achieve unit independence.

The outermost nest (first nest) augments human capital and total investments according to a CES aggregate with age-specific parameter $\kappa^{h}(j)$ and age-independent substitution elasticity $\sigma^{h}$. We set $\sigma^{h}=1,{ }^{24}$ and calibrate $\kappa^{h}(j)$ to match (per child) time investments by age of the child. We model age dependency as

$$
\ln \left(\frac{1-\kappa^{h}(j)}{\kappa^{h}(j)}\right)=\alpha_{0}^{\kappa^{h}}+\alpha_{1}^{\kappa^{h}} \cdot j+\alpha_{1}^{\kappa^{h}} \cdot j^{2}
$$

and determine $\alpha_{1}^{\kappa^{h}}, \alpha_{2}^{\kappa^{h}}$ by an indirect inference approach such that the age pattern of log per child time investments in the data equals the pattern in the model for biological ages 6 to 14 of the child. Recall that we in turn match the average level of time investments at biological ages 6 to 14 by calibrating the utility cost parameter $\kappa$. Time investments at biological age 4 are matched differently, with details described below. The intercept term $\alpha_{0}^{\kappa^{h}}$ is calibrated to match average monetary investments. Consistent with Cunha et al. (2010), we find that the weight on acquired human capital at age $j$ is increasing in $j$, so that investments become less important in the course of the life-cycle. While our model is not directly comparable to their empirical analysis, ${ }^{25}$ also the magnitude of $\kappa^{h}(j)$ is similar.

In the second nest, we restrict $\kappa^{s}(j)=\bar{\kappa}^{s=p u}=\bar{\kappa}^{s=p r}=\bar{\kappa}^{s}$ for $j>0$ and calibrate it exogenously according to the estimates for the US by Kotera and Seshadri (2017)—who estimate

\footnotetext{
${ }^{24}$ That is approximately the mean value of the parameter for young and old children in Cunha et al. (2010)

${ }^{25}$ Total Investments in our model in the first nest include government investments from the second nest, and we do not distinguish explicitly between cognitive and non-cognitive skills.
} 
the parameters of a CES nesting of private and public education investments similar to oursgiving $\bar{\kappa}^{s}=0.676$.

At biological age 4 of the child, children are still in kindergarten. To take into account this structural break in the process of education according to the institutional setting, we separately calibrate $\kappa_{0}^{e}$ to match the average time investments by parents into their children at biological age 4 of the child. This gives $\kappa_{0}^{e}=0.56$.

We restrict the substitution elasticity $\sigma^{s}$ to be the same for private and public schools, $\sigma^{s=p u}=\sigma^{s=p r}$ and calibrate it with reference to Kotera and Seshadri (2017) who estimate an elasticity of substitution between private and government investment of $\sigma^{s}=2.43$. Thus, parental investments $i^{p}(j)$ and government investments $i^{s=p u}(j)$ are gross substitutes but substitution across these education inputs is far from perfect.

$\bar{A}$ is a computational normalization parameter which we choose such that average acquired human capital is equal to 1 , sufficiently below the maximum human capital gridpoint, giving $\bar{A}=$ 1.19 .

The third nest augments the endogenous age specific per child monetary and time investments. As in Lee and Seshadri (2019) we restrict $\sigma^{m}=1$. The age dependency of $\kappa^{m}(j)$ is specified as

$$
\ln \left(\frac{1-\kappa^{m}(j)}{\kappa^{m}(j)}\right)=\alpha_{0}^{\kappa^{m}}+\alpha_{1}^{\kappa^{m}} \cdot j
$$

We calibrate $\alpha_{0}^{\kappa^{m}}$ to achieve the normalization $\kappa^{m}(3)=0.5$, and $\alpha_{1}^{\kappa^{m}}$ is calibrated to match the monetary investment profile, which is relatively flat in the data.

At age $j_{a}$ the human capital process is extended to the high school period (i.e., for all children with education $e=h s$ and $e=c o$ ). Time and monetary investments by parents in this phase of the life-cycle are zero, because children have already left the parental household and the human capital production function at $j=j_{a}, e \in\{h s, c o\}$ is

$$
h^{\prime}(j)=\tilde{A}\left(\kappa^{h}(6) h^{1-\frac{1}{\sigma^{h}}}+\left(1-\kappa^{h}(6)\right)\left(\frac{i^{g}}{\overline{i^{g}}}\right)^{1-\frac{1}{\sigma^{h}}}\right)^{\frac{1}{1-\frac{1}{\sigma^{h}}}} .
$$

We compute $\kappa^{h}(6)$ as a predicted value from the above described regression in (14) and calibrate the additional scaling parameter $\tilde{A}$ such that the ratio of average human capital at $j=6$ (biological age 16) to average human capital at age $j=5$ is equal to the ratio of test scores of ages $16-17$ to age $14-15$ of 1.07 . This gives $\tilde{A}=1.07$. 
The production function in (15) is an approximation as it ignores parental inputs entirely, ${ }^{26}$ reflecting that parental inputs may not be that effective at that age. The specification also ignores that children may invest into the human capital formation themselves, which may be of particular relevance for our main experiment of school closures. We thus regard our model of biological age 16 children as a crude approximation and will accordingly not put a key emphasis on those children when discussing our results. However, it is important for parental decisions at younger child ages that parents do foresee that the human capital process for age 16 children continues when children have left the household, which is our main motivation for extending the human capital accumulation process beyond that age.

\subsection{College Tuition Costs \& Borrowing Constraint of Children}

We base the calibration of college tuition costs and borrowing constraints for college youngsters on Krueger and Ludwig (2016). The net price $\iota$ (tuition, fees, room and board net of grants and education subsidies) for one year of college in constant 2005 dollars is 13,213\$. In 2008 dollars, the maximum amount of publicly provided students loans per year is given by $11,250 \$$, which is the children's borrowing limit in the model for $e=c o$ and $j \in\left[j_{h}, j_{c}-1\right]$. For all ages $j \geq j_{c}$ we let

$$
\underline{\mathrm{a}}(j, c o, c h)=\underline{\mathrm{a}}(j-1, c o, c h)(1+r)-r p(c h)
$$

and compute $r p$ such that the terminal condition $\underline{\mathrm{a}}\left(j_{r}, c o, c h\right)=0$ is met.

\subsection{Government}

The government side features the budget of the general tax and transfer system and a separate budget of the pension system. In the general budget the revenue side is represented by consumption, capital income and labor income taxes. The consumption tax rate is set to $\tau_{c}=5 \%$ based on Mendoza et al. (1994), and the capital income tax rate to $\tau_{k}=20 \%$, which is the current statutory capital income tax rate on long-term capital gains (assets held longer than a year) for households in the highest income tax bracket.

The labor income tax code is approximated by the following two-parameter function, as in, e.g., Benabou (2002) and Heathcote et al. (2017):

$$
T(y)=y-\lambda y^{1-\tau},
$$

\footnotetext{
${ }^{26}$ It would not be possible in our setup to model parental inputs at that age because children have already left the household.
} 
where $\tau$ is the progressivity parameter and $\lambda$ determines the average tax rate. We set $\tau=0.18$ as suggested by estimates of Heathcote et al. (2017) and calibrate $\lambda$ endogenously to close the government budget, giving $\lambda=0.89$.

Exogenous government spending (net of spending on education) is set to $G / Y \%=13.8 \%$. In addition, the government spends on schooling for children and pays the college subsidy for college students. The former we approximate as $5000 \$$ per pupil based on UNESCO (1999-2005) data, as for example in Holter (2015). The latter is set to $38.8 \%$ of average gross tuition costs, as in Krueger and Ludwig (2016). Assuming, as in Krueger and Ludwig (2016), that the difference between net and gross tuition costs is due to both a public and a private subsidy with the latter not being explicitly modelled in our setup ${ }^{27}$ gives an average public subsidy of $\$ 6,119$ per student.

As for the pension system, the payroll tax $\tau^{p}$ is set to the current legislative level of $12.4 \%$ and the pension benefit level relating average pension benefits to average net wages is endogenously chosen such that the benefits of the parent generation equal their contributions, giving a replacement benefit level of $\rho^{p}=0.19$.

\subsection{Calibrating the School Closures Experiments}

The calibration of the length of school closures is based on Table 2 which shows the effective schooling time, as percent of the total available time in the two year interval starting from March 2020, for different groups of students and under different assumptions on the effectiveness of online learning format. The crucial model input is the fraction of instructional time lost due to Covid-19 school closures, which is simply given by 1 minus the respective entry in Table 2. Our benchmark results are derived under the assumption that online schooling formats do not contribute to human capital accumulation, i.e., the first panel of Table 2. We relax that assumption in our sensitivity analysis of Section 8 by assuming a $50 \%$ effectiveness of online formats (third panel of Table 2).

\section{Results}

In this section we document the positive and normative consequences from the differential school closures documented in the empirical part of the paper assuming zero effectiveness of online formats.

\footnotetext{
${ }^{27}$ The private subsidy is set to $16.6 \%$ of average gross tuition costs as in Krueger and Ludwig (2016).
} 


\subsection{Young and Old Children}

In Table 14 we display the impact of the differential school closures on tertiary education attainment, human capital, the present discounted value of future earnings and welfare, broken down by the age of the child. Holding the length of school closures constant, younger children are more adversely affected from the Covid-19 school crisis than older children; as we explained in Fuchs-Schündeln et al. (2021), this is a direct consequence of the self-productivity and dynamic complementarity in the production of human capital. However, as we saw from the empirical section, secondary schools were closed for significantly longer than primary schools. As a consequence of these two competing factors, it is the youngest secondary school children that are most severely affected by the Covid-19 school closures.

Table 14: Aggregate Outcomes for Main Experiments

\begin{tabular}{lcccccccc}
\hline & baseline & \multicolumn{7}{c}{ Change for Children of Biological Age } \\
\hline & & average & 4 & 6 & 8 & 10 & 12 & 14 \\
\hline & \multicolumn{7}{c}{ change in \%p } \\
\hline share $s=n o$ & $12.16 \%$ & 1.55 & 1.10 & 2.22 & 1.77 & 1.79 & 1.38 & 1.06 \\
share $s=h s$ & $54.60 \%$ & 0.36 & 0.24 & -0.23 & 0.22 & 0.54 & 0.67 & 0.69 \\
share $s=c o$ & $33.24 \%$ & -1.91 & -1.34 & -1.99 & -1.99 & -2.33 & -2.05 & -1.76 \\
\hline \multicolumn{7}{c}{ change in \% } \\
\hline av HK & 1.00 & -2.77 & -2.12 & -3.19 & -2.86 & -3.26 & -2.81 & -2.38 \\
PDV gross earn & $\$ 845,149$ & -1.73 & -1.32 & -1.97 & -1.79 & -2.05 & -1.77 & -1.50 \\
PDV net earn & $\$ 695,548$ & -1.39 & -1.05 & -1.59 & -1.44 & -1.64 & -1.41 & -1.19 \\
\hline child CEV & - & $-0.99 \%$ & $-0.77 \%$ & $-1.14 \%$ & $-1.02 \%$ & $-1.17 \%$ & $-1.01 \%$ & $-0.86 \%$ \\
\hline \hline
\end{tabular}

Notes: share $s \in\{n o, h s, c o\}$ : education share in respective education category $s=n o$ : less than high school, $s=h s$ : high school, $s=c o$ : college; av HK: average acquired human capital at age 16; PDV gross earn: present discounted value of gross earnings assuming labor market entry at age 22 and retirement at age 66; PDV net earn: present discounted value of net earnings; CEV: consumption equivalent variation. Columns for biological ages 4-14 show the respective percentage point changes of education shares, the percent changes of acquired human capital and average earnings, and the CEV expressed as a percent change, for children of the respective age at the time of the school closures. Column "average" gives the respective average response. The $\mathrm{CEV}$ is the consumption equivalent variation welfare measure.

\subsection{Public vs. Private Schools}

According to our empirical estimates, private schools were closed significantly shorter than public school. We now quantify the impact of these differences in Tables 15, 16 and 17 which display the differential impact, by school type, of the Covid-19 crisis on human capital, lifetime earnings and welfare (measured in consumption-equivalent variation). 
Table 15: Acquired Human Capital by School Type

\begin{tabular}{lcccccccc}
\hline \hline & baseline & & \multicolumn{4}{c}{ \%-Change for Children of Biological Age } \\
\hline & & average & 4 & 6 & 8 & 10 & 12 & 14 \\
\hline public & 0.96 & -2.87 & -2.22 & -3.30 & -2.92 & -3.39 & -2.93 & -2.48 \\
private & 1.29 & -2.17 & -1.50 & -2.58 & -2.52 & -2.49 & -2.13 & -1.80 \\
\hline \hline
\end{tabular}

First we note that children attending private schools would have higher human capital and lifetime earnings in the absence of the Covid-19 shock, see the second columns of Tables 15 and 16. This is due to the fact that children attending private schools tend to come from affluent parents with higher education that on average invest more into their children (which also tend to have higher initial human capital); this selection effect is compounded by the higher productivity of private schools in the human capital production function.

Table 16: Average gross lifetime earnings by school type

\begin{tabular}{lrccccccc}
\hline \hline & baseline & & \multicolumn{4}{c}{ \%-Change for Children of Biological Age } \\
\hline & & average & 4 & 6 & 8 & 10 & 12 & 14 \\
\hline public & 821,404 & -1.77 & -1.37 & -2.01 & -1.79 & -2.09 & -1.82 & -1.54 \\
private & $1,034,791$ & -1.49 & -0.99 & -1.72 & -1.78 & -1.75 & -1.48 & -1.24 \\
\hline \hline
\end{tabular}

As Table 15 shows, the longer school closings of public schools lead to larger human capital losses from the Covid-19 crisis among its pupils $(-2.87$ vs. -2.17$)$, which translates into larger declines in lifetime earnings (both directly and indirectly though the larger impact on high school and college attendance rates). As Table 16 shows, the net present value of gross lifetime earnings falls by $-1.77 \%$ among children attending public schools, but only $-1.49 \%$ for those in private school. This translates into differential welfare losses for the two groups of $-1.04 \%$ and $-0.64 \%$, respectively, as Table 17 shows.

Table 17: Child CEV by school type

\begin{tabular}{lccccccc}
\hline \hline & average & 4 & 6 & 8 & 10 & 12 & 14 \\
\hline public & $-1.04 \%$ & $-0.81 \%$ & $-1.19 \%$ & $-1.05 \%$ & $-1.22 \%$ & $-1.06 \%$ & $-0.90 \%$ \\
private & $-0.64 \%$ & $-0.43 \%$ & $-0.75 \%$ & $-0.71 \%$ & $-0.73 \%$ & $-0.64 \%$ & $-0.55 \%$ \\
\hline \hline
\end{tabular}




\subsection{Income-Rich vs. Income Poor Households}

One of the most intriguing and perhaps surprising empirical findings was that children in incomepoorer regions (counties) saw their schools closed for shorter periods than their brethren in more affluent places. We now quantify the differential welfare impact of these observations using our structural model.

Table 18: Child CEV: Bottom, Top Parental Income Quartile, Homogeneous Schooling Inputs

\begin{tabular}{lccccccc}
\hline \hline & average & 4 & 6 & 8 & 10 & 12 & 14 \\
\hline bottom & $-1.30 \%$ & $-1.09 \%$ & $-1.49 \%$ & $-1.31 \%$ & $-1.51 \%$ & $-1.30 \%$ & $-1.10 \%$ \\
top & $-0.53 \%$ & $-0.33 \%$ & $-0.59 \%$ & $-0.54 \%$ & $-0.63 \%$ & $-0.57 \%$ & $-0.52 \%$ \\
\hline \hline
\end{tabular}

Comparing children from the top- to children from the bottom quartile of the income distribution, welfare losses are 0.77 percentage points larger for the poorer children if school closures were unrelated to income $(-1.30 \%$ compared to $-0.53 \%)$, see Table 18 . Accounting for the longer school closures in richer counties reduces this gap to 0.54 percentage points $(-1.11 \%$ compared to $-0.57 \%$ ), as documented in Table 19. Therefore, although poorer children are still more severely affected by the pandemic, this force reduces the gap by about $1 / 3$ ( 0.54 versus 0.77 percentage points).

Table 19: Child CEV: Bottom, Top Parental Income Quartile, Heterogeneous Schooling Inputs

\begin{tabular}{lccccccc}
\hline \hline & average & 4 & 6 & 8 & 10 & 12 & 14 \\
\hline bottom & $-1.11 \%$ & $-0.93 \%$ & $-1.29 \%$ & $-1.13 \%$ & $-1.27 \%$ & $-1.10 \%$ & $-0.93 \%$ \\
top & $-0.57 \%$ & $-0.35 \%$ & $-0.61 \%$ & $-0.57 \%$ & $-0.69 \%$ & $-0.63 \%$ & $-0.58 \%$ \\
\hline \hline
\end{tabular}

\section{Counterfactual Policy Analysis}

In this section we conduct counterfactual policy experiments. Specifically, we evaluate the consequences of keeping the schools open for an additional 3 months in the two year period following the Covid-19 pandemic; this corresponds to one full summer or two half summers of additional schooling starting in 2022. 


\subsection{Fiscal Consequences of the Covid-19 Induced Human Capital Losses}

To give this thought experiment some context, in Table 20 we report the consequences for tax revenues from the school closures reported in the previous subsection. It is clear that, on account of the massive decline in future labor income taxes, the fiscal situation of the government deteriorates significantly. Overall, tax revenues fall by almost $2.5 \%$ relative to pre-Covid-19 times.

Table 20: Change of Present Discounted Value of Tax Revenues [in \%]

\begin{tabular}{ccccc}
\hline \hline Revenue source & All & Lab. Inc. & Cap. Inc. & Cons. \\
\hline & -2.44 & -7.10 & 0.23 & -0.95 \\
\hline \hline
\end{tabular}

Notes: The table shows the change in the present discounted value of tax revenue (in \%). Revenue source: All: sum of all tax sources; lab.: from labor income taxes; cap.: from capital income taxes; cons.: from consumption taxes.

\subsection{National Schooling Expansion}

This raises the question whether keeping schools open in the summer to partially compensate for the human capital losses is a positive net present value proposition. Table 21 shows that, on average across households, the net present value of the future labor income gain from the intervention net of the cost of the schooling extension is positive at $\$ 1,018$. Alternatively put, for each of the $\$ 1,396$ spent on each child, the present discounted value of that child's lifetime earning increases by $\$ 1.73$, for a total gain of $\$ 2,414$. As Table 22 shows, the welfare gain for the average child from this intervention amounts to $0.21 \%$ of lifetime consumption. In other words, a national 3 months schooling expansion compensates for more than $1 / 5$ of the welfare losses of children induced by the Covid-19 shock. ${ }^{28}$

Table 21: NPV of Intervention for the Household Sector

\begin{tabular}{lcccccccc}
\hline \hline & baseline & \multicolumn{4}{c}{ Abs Change for Children of Biological Age } \\
\hline & & average & 4 & 6 & 8 & 10 & 12 & 14 \\
\hline NPV household (in \$) & 0.00 & 1,018 & 1,487 & 1,347 & 1,170 & 948 & 726 & 428 \\
\hline \hline
\end{tabular}

\footnotetext{
${ }^{28}$ Note that if the goal of the government would be to fully offset the welfare losses that affected children incur as a result of school closures then the public schooling input during the 2 years following the lockdown of schools would have to be increased by ca. $67 \%$, taking into account the crowding-out of parental investments as well as the fact that the human capital production function exhibits self-productivity and dynamic complementarity, and thus the Covid-19 schooling losses make future investments into human capital less productive.
} 
Table 22: (Net) Child CEV: Intervention

\begin{tabular}{lccccccc}
\hline \hline & average & 4 & 6 & 8 & 10 & 12 & 14 \\
\hline (Net) CEV children: Intervention & $0.21 \%$ & $0.29 \%$ & $0.26 \%$ & $0.22 \%$ & $0.19 \%$ & $0.16 \%$ & $0.14 \%$ \\
\hline \hline
\end{tabular}

The government, though the tax system, of course only captures a part of the increase in the net present value of earnings. As Table 23 shows, the reform turns out to be approximately self-financing in net present value terms and, therefore, there is no impact of the reform on the government budget.

Table 23: NPV of Intervention: Government

\begin{tabular}{ccccccccc}
\hline \hline & baseline & \multicolumn{4}{c}{ Abs Change for Children of Biological Age } \\
\hline & & average & 4 & 6 & 8 & 10 & 12 & 14 \\
\hline NPV government & 0.00 & -0.00 & 0.16 & 0.11 & 0.05 & -0.04 & -0.13 & -0.15 \\
\hline \hline
\end{tabular}

Table 24 shows the drop in the present discounted value of tax revenues following the afterCovid schooling expansion. Recall from Table 20 that the Covid shock reduces future tax revenue by $2.4 \%$. This loss is reduced to $1.9 \%$ by the schooling intervention, as Table 24 demonstrates. Thus, even though this policy reform approximately pays for itself (given the assumptions on the cost of the schooling expansion), it is insufficient to raise tax revenues to pre-Covid levels. Larger, longer lasting schooling interventions would be necessary to achieve that objective.

Table 24: Change of Present Discounted Value of Tax Revenues: Covid Shock and PostCovid Schooling Expansion [in \%]

\begin{tabular}{ccccc}
\hline \hline Revenue source & All & Lab. Inc. & Cap. Inc. & Cons. \\
\hline & -1.94 & -5.72 & 0.22 & -0.75 \\
\hline
\end{tabular}

Notes: The table shows the change in the present discounted value of tax revenue (in \%). Revenue source: All: sum of all tax sources; lab.: from labor income taxes; cap.: from capital income taxes; cons.: from consumption taxes.

\subsection{Schooling Expansion for Selected Subgroups of the Population}

Next, we consider the question which groups to prioritize, in terms of additional schooling. We consider the two income groups of parents studied in Section 6.3 and ask which group of children 
to prioritize if scarcity of school buildings, availability of teachers or other constraints makes an expansion of school for the entire children population infeasible, or too large a program from a fiscal perspective. The answer to this question is not obvious: on one hand, children from poorer families accumulate less human capital and have lower lifetime utilities to start with even without the Covid-19 school closures, and sustain larger welfare losses than income-rich children, although the shorter school closures (relative to those of income richer children) mitigate this gap somewhat, see Section 6.3. This suggests that poorer children would reap larger benefits from the additional schooling, an argument that underlies most policy proposals for selective school expansions in the U.S. On the other hand, precisely because children from income-richer families accumulate more human capital and have a higher propensity to go to college pre-Covid-19, they tend to have higher earnings and pay more taxes. Therefore, from a fiscal perspective it might be this group whose Covid-19-induced loss of human capital an expansion of schooling should tackle.

Table 25: NET Child CEV: Bottom and Top Parental Income Quartile, Heterogeneous Schooling Inputs

\begin{tabular}{lccccccc}
\hline \hline & average & 4 & 6 & 8 & 10 & 12 & 14 \\
\hline bottom & $0.28 \%$ & $0.41 \%$ & $0.36 \%$ & $0.31 \%$ & $0.26 \%$ & $0.22 \%$ & $0.14 \%$ \\
top & $0.09 \%$ & $0.08 \%$ & $0.10 \%$ & $0.09 \%$ & $0.08 \%$ & $0.07 \%$ & $0.13 \%$ \\
\hline \hline
\end{tabular}

Tables 25 and 26 show the results, and indeed confirm that implementing a school summer program in the next two summers has a significantly positive welfare impact on children, and that these welfare gains are especially large for younger children from poorer parental backgrounds. As a potentially desirable side effect, earnings and welfare inequality would fall under such a selective school expansion policy.

On the other hand, the budgetary consequences of such a school expansion are much more favorable if focused on children from more affluent social backgrounds. Table 26, which displays the per-child ${ }^{29}$ fiscal consequences from the school expansion shows that the typical child from a poor parental background pays an additional $\$ 1,396-\$ 146=\$ 1,250$ of taxes due to higher human capital induced by the schooling reform, whereas for an affluent child the same number is $\$ 1,470$. Therefore a government exclusively concerned about the fiscal impact of the reform

\footnotetext{
${ }^{29}$ Even though the top and bottom quartile of the parental income distribution has the same number of parents and the school expansion costs the same per child by assumption, the total size of the program differs slightly if bestowed upon the poor and the rich children, since income poorer parents have on average slightly more children.
} 
would select the top-, rather than the bottom quarter of the parental income distribution as the target for the reform.

Table 26: NPV Government (in \$): Bottom and Top Parental Income Quartile, Heterogeneous Schooling Inputs

\begin{tabular}{lrrrrrrr}
\hline \hline & average & 4 & 6 & 8 & 10 & 12 & 14 \\
\hline bottom & -147 & 129 & 42 & -50 & -155 & -273 & -574 \\
top & 74 & 196 & 192 & 84 & -48 & -177 & 200 \\
\hline \hline
\end{tabular}

\section{Sensitivity Analysis}

In this section we document the sensitivity of our results with respect to the effectiveness of virtual learning formats. Thus far we had assumed that students learning online do not accumulate any human capital. This assumption can reflect the low productivity of online learning, the missing IT infrastructure at home even when online learning is offered and in principle effective, or the adverse effects of being on electronic devices constantly that negate any positive human capital accumulation. We now display selected results under the assumption that online learning format are partially effective in imparting human capital on students.

\subsection{Consequences of Smaller Effective School Closures}

In Table 2 of Section 3 we summarized effective schooling times during the 2020-2021 period. The baseline results thus far were derived under the results in the first panel; now we use the numbers from the third panel, which assume a $50 \%$ effectiveness of online formats. Qualitatively, under this assumption school closures are shorter, and the dispersion in school closures by school types (public vs. private and primary vs. secondary) and county income is smaller. To give one summary measure, if virtual learning is completely ineffective, the loss in schooling input (averaged over all school types) was $40.8 \%$ over a two year period, and with $50 \%$ effectiveness this number is roughly cut in half, to $20.6 \%$ (compare the first entries in the first and third panel of Table 2, respectively).

Table 27 displays the consequences for educational attainment, human capital, the present discounted value of earnings and welfare measured in terms of consumption-equivalent variation. Compared to the benchmark results in Table 14 we see that all qualitative results from Section 6 remain fully intact, but its magnitudes become smaller, which is to be expected because the 
effective size of the negative schooling shock is roughly cut in half. Interestingly, the reduction in the negative impact on human capital, earnings and welfare is less than half its previous magnitude. In our model, where future human capital accumulation depends positively on current human capital (due to self-productivity and dynamic complementarity in the human capital production function), the costs of school closures are strictly convex in its length. The results in Table 27 exactly display this feature.

Table 27: Aggregate Outcomes for Main Experiments: 50\% Effectiveness of Virtual Learning

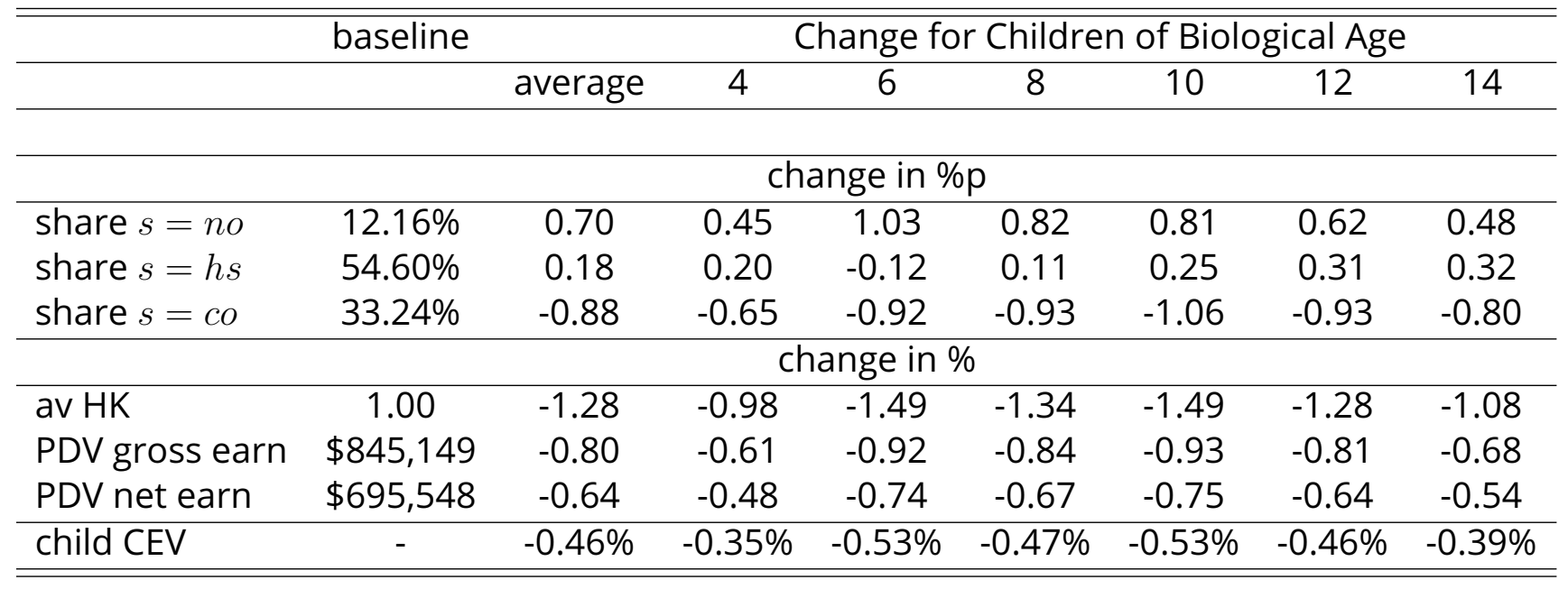

The same observation applies to the differences in lifetime earnings and welfare across children attending public versus private schools. Table 2 of Section 3 shows that if online educational formats are somewhat effective substitutes for in-person learning, then the gap across these school types in the effective length if school closures shrinks, and so do the differences in the earnings and welfare losses between its graduates, as can be gauged by comparing Tables 28 and 29 with their counterparts, Tables 16 and 17 from Section 6.

Table 28: Average gross lifetime earnings by school type

\begin{tabular}{lcccccccc}
\hline \hline & baseline & \multicolumn{6}{c}{ \%-Change for Children of Biological Age } \\
\hline & & average & 4 & 6 & 8 & 10 & 12 & 14 \\
\hline public & 821403.99 & -0.81 & -0.63 & -0.94 & -0.84 & -0.95 & -0.82 & -0.70 \\
private & 1034790.88 & -0.70 & -0.47 & -0.78 & -0.84 & -0.82 & -0.69 & -0.58 \\
\hline \hline
\end{tabular}

Finally, Table 30 shows welfare losses of children whose parents are in the bottom and the top quartile of the income distribution, respectively. Compared to Table 19 from Section 6, under the 
Table 29: Child CEV by school type

\begin{tabular}{lccccccc}
\hline \hline & average & 4 & 6 & 8 & 10 & 12 & 14 \\
\hline public & $-0.48 \%$ & $-0.37 \%$ & $-0.56 \%$ & $-0.49 \%$ & $-0.56 \%$ & $-0.48 \%$ & $-0.41 \%$ \\
private & $-0.30 \%$ & $-0.21 \%$ & $-0.35 \%$ & $-0.34 \%$ & $-0.34 \%$ & $-0.30 \%$ & $-0.26 \%$ \\
\hline \hline
\end{tabular}

assumption of $50 \%$ effectiveness of virtual learning the magnitude of welfare losses is smaller for both groups and the difference between the two groups shrinks as well (as does the share of the gap under homogeneous school closure lengths that is being closed due to low-income regions experiencing shorter school closures).

Table 30: Child CEV: Bottom, Top Parental Income Quartile, Heterogeneous Schooling Inputs

\begin{tabular}{lccccccc}
\hline \hline & average & 4 & 6 & 8 & 10 & 12 & 14 \\
\hline bottom & $-0.51 \%$ & $-0.42 \%$ & $-0.61 \%$ & $-0.54 \%$ & $-0.59 \%$ & $-0.51 \%$ & $-0.43 \%$ \\
top & $-0.26 \%$ & $-0.16 \%$ & $-0.28 \%$ & $-0.27 \%$ & $-0.31 \%$ & $-0.28 \%$ & $-0.26 \%$ \\
\hline \hline
\end{tabular}

\subsection{School Time Extensions}

Perhaps most importantly, how do shorter and less dispersed effective school closures impact the positive and normative implications of government schooling interventions from Section 7 ? Table 31 summarizes the welfare consequences from the reform (measured again in terms of consumption equivalent variation), and Tables 32 and 33 show the fiscal consequences for private households and the government, respectively.

Table 31: (Net) Child CEV: Intervention

\begin{tabular}{lccccccc}
\hline \hline & average & 4 & 6 & 8 & 10 & 12 & 14 \\
\hline (Net) CEV children: Intervention & $0.21 \%$ & $0.30 \%$ & $0.26 \%$ & $0.23 \%$ & $0.19 \%$ & $0.16 \%$ & $0.15 \%$ \\
\hline \hline
\end{tabular}

Compared to the benchmark results, with lower schooling losses the impact of additional schooling in the summer on the present discounted value of household earnings and tax revenues is somewhat larger (so that the intervention now generates net revenue for the government, although its magnitude is relatively small at $\$ 26$ per capita). The welfare gains for children from 
Table 32: NPV of Intervention for the Household Sector

\begin{tabular}{lcccccccc}
\hline \hline & baseline & & \multicolumn{4}{c}{ Abs Change for Children of Biological Age } \\
\hline & & average & 4 & 6 & 8 & 10 & 12 & 14 \\
\hline NPV Household & 0.00 & 1057.74 & 1517.21 & 1391.98 & 1212.46 & 998.63 & 766.41 & 459.74 \\
\hline \hline
\end{tabular}

Table 33: NPV of Intervention: Government

\begin{tabular}{lcccccccc}
\hline & baseline & & \multicolumn{4}{c}{ Abs Change for Children of Biological Age } \\
\hline & & average & 4 & 6 & 8 & 10 & 12 & 14 \\
\hline NPV Government & 0.00 & 25.55 & 248.21 & 179.62 & 90.20 & -23.42 & -150.53 & -190.75 \\
\hline \hline
\end{tabular}

the intervention are also marginally larger, but by and large the quantitative consequences of the schooling expansion are robust to starting with shorter school closures than in the benchmark.

\section{Conclusion}

In this paper we have documented, using Safegraph cell phone data, that the Covid-19 crisis led to lengthy school closures that are substantially heterogeneous across school types (primary vs. secondary schools and public vs. private schools). Using a structural life cycle model with private and public school choice and parental time and resource investment into their children and empirically informing it with the school closure data we estimate the human capital- and welfare losses of different characteristics. We then use the model to evaluate the fiscal and welfare consequences of recent policy proposals that will extend instructional time in the next two summers by three months total to partially compensate for these losses. Such a policy reform raises welfare of children and approximately pays for itself by generating higher future labor income- and consumption taxes.

We fully acknowledge that the results in this paper should not be interpreted as a fully costbenefit analysis of school closures. Such an analysis would have to model the potential short-run health benefits, in the form of reduced Covid-19 transmissions in schools, that motivated school closures in the first place. Integrating our framework into a standard EPI-Econ model of the Covid-19 crisis (of the form discussed in the literature section of this paper) is therefore a natural next step for future research, in our view. 


\section{References}

Abbott, B., G. Gallipoli, C. Meghir, and G. L. Violante (2019). Education Policies and Intergenerational Transfers in Equilibrium. Journal of Political Economy 127(6), 2569-2624.

Acemoglu, D., V. Chernozhukov, I. Werning, and M. Whinston (2020). Optimal targeted lockdowns in a multi-group sir model. Working Paper, MIT.

Agostinelli, F., M. Doepke, G. Sorrenti, and F. Zilibotti (2020). When the Great Equalizer Shuts Down: Schools, Peers, and Parents in Pandemic Times. NBER Working Paper 28264.

Alemán, C., C. Busch, A. Ludwig, and R. Santaeulàlia-Llopis (2021). Evaluating the Effectiveness of Policies Against a Pandemic. CEPR Discussion Paper 15390.

Allcott, H., L. Boxell, J. Conway, M. Gentzkow, M. Thaler, and D. Yang (2020). Polarization and public health: Partisan differences in social distancing during the coronavirus pandemic. Journal of Public Economics 191, 23-62.

Argente, D., F. Alvarez, and F. Lippi (2020). A simple planning problem for covid-19 lockdown and smart tracing. Working Paper, University of Chicago.

Atkeson, A. (2020, March). What will be the economic impact of covid-19 in the us? rough estimates of disease scenarios. Working Paper 26867, National Bureau of Economic Research.

Benabou, R. (2002). Tax and Education Policy in a Heterogeneous-Agent Economy: What Levels of Redistribution Maximize Growth and Efficiency? Econometrica 70(2), 481-517.

Bravata, D., J. H. Cantor, N. Sood, and C. M. Whaley (2021). Back to school: The effect of school visits during covid-19 on covid-19 transmission. Technical report, National Bureau of Economic Research.

Brotherhood, L., P. Kircher, C. Santos, and M. Tertilt (2020). An economic model of the covid-19 pandemic with young and old agents: Behavior, testing and policies. Working Paper, University of Mannheim.

Busch, C. and A. Ludwig (2020). Higher-Order Income Risk over the Business Cycle. Working Paper.

Carlsson, M., G. B. Dahl, B. Öckert, and D.-O. Rooth (2015). The Effect of Schooling on Cognitive Skills. Review of Economics and Statistics 97(3), 533-547. 
Caucutt, E. and L. Lochner (2020). Early and Late Human Capital Investments, Borrowing Constraints, and the Family. Journal of Political Economy 128(3), 1065-1147.

Caucutt, E. M., L. Lochner, J. Mullins, and Y. Park (2020). Child Skill Production: Accounting for Parental and Market-Based Time and Goods Investments. NBER Working Paper 27838.

Chernozhukov, V., H. Kasahara, and P. Schrimpf (2021). Causal impact of masks, policies, behavior on early covid-19 pandemic in the us. Journal of econometrics 220(1), 23-62.

Cunha, F. and J. Heckman (2007). The Technology of Skill Formation. The American Economic Review 97(2), 31-47.

Cunha, F., J. Heckman, and L. Lochner (2006). Interpreting the Evidence on Life Cycle Skill Formation. Handbook of the Economics of Education, Vol. 1 (Erik Hanushek and Finis Welch, eds) (chapter 12), 697-812.

Cunha, F., J. J. Heckman, and S. M. Schennach (2010). Estimating the Technology of Cognitive and Noncognitive Skill Formation. Econometrica 78(3), 883-931.

Daruich, D. (2020). The Macroeconomic Consequences of Early Childhood Development Policies. Working Paper.

Dorn, E., B. Hancock, J. Sarakatsannis, and E. Viruleg (2021). Covid-19 and education: The lingering effects of unfinished learning. Technical report, McKinsey \& Company.

Eichenbaum, M., S. Rebelo, and M. Trabandt (2020). The macroeconomics of epidemics'. Iondon, centre for economic policy research. CEPR DP 14520.

Fernandez-Villaverde, J. and C. Jones (2020). Estimating and simulating a sirdmodel of covid-19 for many countries, states, and cities. Working Paper, Stanford University.

Fitzpatrick, M. D., D. Grissmer, and S. Hastedt (2011). What a Difference a Day Can Make: Estimating Daily Learning Gains during Kindergarten and First Grade Using a Natural Experiment. Economics of Education Review 30(2), 269-279.

Fuchs-Schündeln, N., D. Krueger, A. Ludwig, and I. Popova (2021). The Long-Term Distributional and Welfare Effects of COVID-19 School Closures. Working Paper.

Glover, A., J. Heathcote, D. Krueger, and J.-V. Rios-Rull (2020). Health versus Wealth: On the Distributional Effects of Controlling a Pandemic. Working Paper.

Goolsbee, A. and C. Syverson (2021). Fear, lockdown, and diversion: Comparing drivers of pandemic economic decline 2020. Journal of Public Economics 193, 104311. 
Greenstone, M. and V. Nigam (2020). Does social distancing matter? (March 30, 2020). University of Chicago, Becker Friedman Institute for Economics Working Paper No. 2020-26. Available at SSRN: https://ssrn.com/abstract=3561244 or http://dx.doi.org/10.2139/ssrn.3561244.

Heathcote, J., F. Perri, and G. L. Violante (2010). Unequal We Stand: An Empirical Analysis of Economic Inequality in the United States, 1967-2006. Review of Economic Dynamics 13(1), $15-51$.

Heathcote, J., K. Storesletten, and G. L. Violante (2017). Optimal Tax Progressivity: An Analytical Framework. Quarterley Journal of Economics 132(4), 1693-1754.

Holter, H. A. (2015). Accounting for Cross-Country Differences in Intergenerational Earnings Persistence: The Impact of Taxation and Public Education Expenditure. Quantitative Economics 6(2), 385-428.

Jang, Y. and M. Yum (2021). Aggregate and Intergenerational Implications of School Closures: A Quantitative Assessment. Working Paper.

Jaume, D. and A. Willén (2019). The Long-Run Effects of Teacher Strikes: Evidence from Argentina. Journal of Labor Economics 37(4), 1097-1139.

Kogan, V. and S. Lavertu (2021). How the covid-19 pandemic affected student learning in ohio: Analysis of spring 2021 ohio state tests. Technical report.

Kotera, T. and A. Seshadri (2017). Educational Policy and Intergenerational Mobility. Review of Economic Dynamics 25, 187-207.

Krueger, D. and A. Ludwig (2016). On the Optimal Provision of Social Insurance: Progressive Taxation versus Education Subsidies in General Equilibrium. Journal of Monetary Economics 77, 72-98.

Krueger, D., H. Uhlig, and T. Xie (2020). Macroeconomic dynamics and reallocation in an epidemic. Centre for Economic Policy Research DP 14607.

Kurmann, A. and E. Lalé (2021). School closures and effective in-person learning during covid-19: When, where, and for whom. Technical report.

Kurmann, A., E. Lalé, and L. Ta (2021). The impact of covid-19 on small business dynamics and employment: Real-time estimates with homebase. Technical report. 
Lavy, V. (2015). Do Differences in Schools' Instruction Time Explain International Achievement Gaps? Evidence from Developed and Developing Countries. Economic Journal 125(588), F397-F424.

Lee, S. Y. and A. Seshadri (2019). On the Intergenerational Transmission of Economic Status. Journal of Political Economy 127(2), 855-921.

Lewis, K., M. Kuhfeld, E. Ruzek, and A. McEachin (2021). Learning during covid-19: Reading and math achievement in the 2020-21 school year. Technical report, NWEA Center for School and Student Progress.

Mendoza, E. G., A. Razin, and L. L. Tesar (1994). Effective Tax Rates in Macroeconomics. CrossCountry Estimates of Tax Rates on Factor Incomes and Consumption. Journal of Monetary Economics 34(3), 297-323.

Moll, B., G. Kaplan, and G. Violante (2020). Pandemics according to hank. Virtual Presentation on March 31, 2020.

Parolin, Z. and E. K. Lee (2021). Large socio-economic, geographic and demographic disparities exist in exposure to school closures. Nature Human Behaviour 5, 522-528.

Pischke, J.-S. (2007). The Impact of Length of the School Year on Student Performance and Earnings: Evidence from the German Short School Years. Economic Journal 523, 1216-1242.

Rivkin, S. G. and J. C. Schimann (2015). Instruction Time, Classroom Quality, and Academic Achievement. Economic Journal 125(588), F425-F448.

Siegel, J. J. (2002). Stocks for the Long Run : The Definitive Guide to Financial Market Returns and Long-Term Investment Strategies. New York: McGraw-Hill.

Yum, M. (2020). Parental Time Investment and Intergenerational Mobility. Working Paper. 


\section{A Dynamic Programs of the Model}

\section{A.1 Children Generation}

\section{A.1.1 Retirement Phase}

In retirement, households of both generations solve the following completely standard recursive consumption-saving problem of the form:

$$
V(j, e, s i, \eta ; a, h)=\max _{c, a^{\prime} \geq 0}\left\{u(c)+\beta V\left(j+1, e, s i, \eta ; a^{\prime}, h\right)\right\}
$$

subject to

$$
\begin{aligned}
c\left(1+\tau^{c}\right)+a^{\prime} & =a\left(1+r\left(1-\tau^{k}\right)\right)+y-T(y) \\
y & =\operatorname{pen}\left(e, s i, \eta_{j_{r}-1}, h\right) \\
\eta & =\eta_{j_{r}-1}
\end{aligned}
$$

where $u($.$) is a standard period utility function that is strictly increasing, strictly concave and twice$ differentiable. Here, pen $\left(e, m, \eta_{j_{r}-1}, h\right)$ is pension income, whose dependence on educational attainment $e$, marital status, the persistent income state in the period prior to retirement $\eta_{j_{r}-1}$ and human capital $h$ serves to proxy for the progressive nature of the social security system. More precisely, for the children generation we have assumed that all individuals remain single (and thus pensions are $\operatorname{pen}\left(e, s i, \eta_{j_{r}-1}, h\right)$ ), and for the parental generation we will normalized human capital to 1 , so that pension benefits are independent of $h$, so that $\operatorname{pen}\left(e, m, \eta_{j_{r}-1}\right)$, see below. Apart from these differences in the exact form of the pension benefits formula, the retirement decision problems of both generations are identical.

\section{A.1.2 Working Phase}

During working life, the dynamic programming problem of the children generation reads as

$$
V(j, e, \eta, \varepsilon, a, h)=\max _{c, a^{\prime}}\left\{u(c)-v(\ell(s i))+\beta \sum_{\eta^{\prime}} \pi\left(\eta^{\prime} \mid \eta\right) \sum_{\varepsilon^{\prime}} \psi\left(\varepsilon^{\prime}\right) V\left(j+1, e, \eta^{\prime}, \varepsilon^{\prime}, a^{\prime}, h\right)\right\}
$$


subject to the constraints

$$
\begin{aligned}
c\left(1+\tau^{c}\right)+a^{\prime} & =a\left(1+r\left(1-\tau^{k}\right)\right)+y\left(1-\tau^{p}\right)-T\left(y\left(1-0.5 \tau^{p}\right)\right) \\
y & =w \gamma(e, h) \epsilon(e, j, s i) \eta \varepsilon \ell(s i) \\
a^{\prime} & \geq-\underline{a}(j, e, c h)
\end{aligned}
$$

Since labor supply is exogenous in our model, the disutility of work $v(\cdot)$ does not affect optimal choices of children, but impacts the child value functions which in turn enter the parental transfer decision problem as spelled out in the main text. Income $y$ depends on permanent labor productivity $\gamma(e, h)$ which in turn is a function of human capital acquired during the child's schooling years as well as the chosen level of education $e$.

\section{A.1.3 Education Decision and Phase}

The dynamic programs for this phase of the children's life cycle were explicitly spelled out in the main text.

\section{A.2 Parental Generation}

\section{A.2.1 Retirement Phase}

The retirement phase of the parental generation is a standard consumption-saving problem of the form

$$
V(j, e, m, \eta ; a)=\max _{c, a^{\prime} \geq 0}\left\{u\left(\frac{c}{1+\mathbf{1}_{m=m a} \zeta_{a}}\right)+\beta V\left(j+1, e, m, \eta ; a^{\prime}\right)\right\}
$$

subject to

$$
\begin{aligned}
c\left(1+\tau^{c}\right)+a^{\prime} & =a\left(1+r\left(1-\tau^{k}\right)\right)+y-T(y) \\
y & =\operatorname{pen}\left(e, m, \eta_{j_{r}-1}\right) \\
\eta & =\eta_{j_{r}-1}
\end{aligned}
$$

\section{A.2.2 Working Phase}

After children have left the household, the parent generation solves, at age $j \in\left\{j_{a}+j_{f}+\right.$ $\left.1, \ldots, j_{r}-1\right\}$ a standard consumption-savings problem during the rest of working life, similar to the one by the children generation in Section A.1.2. As with the retirement phase, the main difference to the children generation is that now both household income as well as effective per 
capita consumption and labor supply depends on whether a household is single or married. The recursive problem then reads as

$$
\begin{aligned}
V(j, e, m, \eta, \varepsilon, a)= & \max _{c, a^{\prime}}\left\{u\left(\frac{c}{1+\mathbf{1}_{m=m a} \zeta_{a}}\right)\right. \\
& \left.-v\left(\frac{\ell(m)}{1+\mathbf{1}_{m=m a}}\right)+\beta \sum_{\eta^{\prime}} \pi\left(\eta^{\prime} \mid \eta\right) \sum_{\varepsilon^{\prime}} \psi\left(\varepsilon^{\prime}\right) V\left(j+1, e, m, \eta^{\prime}, \varepsilon^{\prime}, a^{\prime}\right)\right\}
\end{aligned}
$$

subject to

$$
\begin{aligned}
& c\left(1+\tau^{c}\right)+a^{\prime}=a\left(1+r\left(1-\tau^{k}\right)\right)+y\left(1-\tau^{p}\right)-T\left(y\left(1-\tau^{p}\right)\right) \\
& y=w \epsilon(e, j, m) \eta \varepsilon \ell(m) \\
& a^{\prime} \geq-\underline{a}(j, e, m, p a) .
\end{aligned}
$$

\section{A.2.3 Inter-Vivos Transfer, Human Capital Investment and Private Schooling Deci- sions}

The dynamic programs for these decisions were given directly in the text since they are the main focus of the model. 


\section{B Data Appendix}

To obtain information about elementary and secondary schools, we use two datasets from the National Center for Education Statistics (NCES).

The first dataset is the Common Core of Data (CCD), which is comprehensive database of all public elementary and secondary schools and school districts (including public charter schools). The CCD consists of different surveys completed annually by state education departments from their administrative records. We use the 2019-2020 CCD school data files released in March 2021.

The other dataset is the NCES's Private School Universe Survey (PSS). PSS is a biennial survey that collects data on private schools and serves as a sampling frame for other NCES surveys of private schools. The schools surveyed in the PSS come with a survey weight (which we use in our construction of sample weights presented in the next section). We use the 2017-2018 data files released in August 2019. This is the most recent version of PSS as of this writing.

We combine the pooled CCD-PSS dataset to the Safegraph dataset of POls with NAICS code 611110 . We first pre-clean the data by standardizing school names and addresses (i.e. we convert the capital letters to lower case, remove non-alphanumeric characters and spaces, etc.). Then, we attempt direct merges on combinations of school names, addresses and zip codes. For those schools that do not have a direct merge, we apply fuzzy-name matching within the same zip code and retain those matches with a high-confidence matching scores. For private schools, we only have school names and GPS coordinates. We match them to the Safegraph data by using a combination of Levenshtein distance between school name and geographic distance based on the GPS coordinates.

Table 34 compares the schools of the pooled CCD-PSS dataset to the subset of schools

matched to Safegraph data. As can be seen, all the observable characteristics of schools line up closely with each other. 
Table 34: Comparison between all schools and schools matched to SG data

\begin{tabular}{lcccc}
\hline & \multicolumn{2}{c}{ Public schools } & \multicolumn{2}{c}{ Private schools } \\
& All & Matched & All & Matched \\
\hline Sample count & & & & \\
& 101,688 & 85,210 & 22,895 & 17,482 \\
Student-teacher ratio & 15.68 & 15.55 & 10.53 & 10.45 \\
& & & & \\
\% Male & 52.2 & 52.1 & 52.5 & 52.6 \\
& & & & \\
\% Indian & 1.84 & 1.68 & 0.72 & 0.70 \\
\% Asian & 3.87 & 3.88 & 6.06 & 5.75 \\
\% Pacific & 0.40 & 0.34 & 0.52 & 0.52 \\
\% Hispanic & 25.2 & 24.5 & 11.7 & 11.8 \\
\% White & 49.9 & 51.5 & 65.0 & 65.9 \\
\% Black & 14.6 & 13.7 & 11.6 & 11.1 \\
\% Other & 4.29 & 4.34 & 4.34 & 4.32 \\
& & & & \\
\% Free lunch & 44.2 & 43.8 & n.a. & n.a. \\
\% Reduced-price lunch & 5.07 & 5.14 & n.a. & n.a. \\
City & & & & \\
Suburban & 27.6 & 26.0 & 34.0 & 34.9 \\
Town & 31.4 & 31.9 & 37.9 & 36.9 \\
Rural & 13.2 & 13.7 & 8.73 & 9.95 \\
& 27.8 & 28.4 & 19.4 & 18.3 \\
& & & &
\end{tabular}

Notes: \% Free lunch and \% Reduced-price lunch denote the share of students who are eligible for free and reduced-price lunches, respectively. 
Figure 6: Aggregate time series of visits (week 1 = 1st week of 2020)

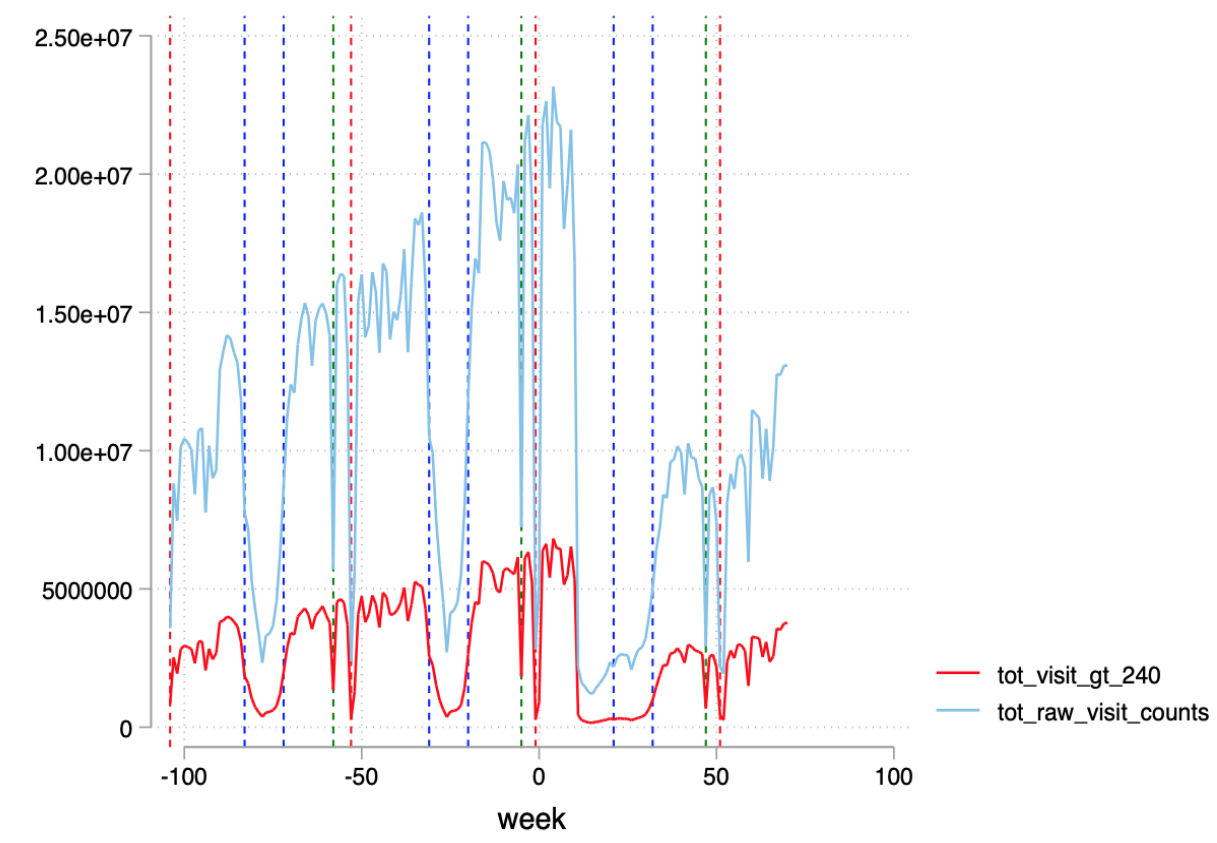

\section{B.1 Further Sample Selection and Sample Weights}

In an effort to reduce noise further, we implement the following additional sample restrictions:

1. We drop schools where the raw visits count on average during the base period is less than 10 , and schools where $d_{j, t}$ is larger than 50 more than once during the based period. The goal of these first two restrictions is to ensure that the measurement of school visits for the base period are reliable enough to compare them with school visits in any other period. Together these restrictions reduce the sample size by $20 \%$.

2. We drop schools where $d_{j, t}$ is larger than 75 more than once, either during the period from beginning of September 2019 to November 2019 or the period from beginning of September 2020 to the end of the sample period (currently end of May). This procedure intends to purge the data from extreme values that affect the average of changes in visits in any given period. We use a larger threshold (75 instead of 50) to trim the data because it is to expected that the visits time series for each school are more volatile outside of the base period. This sample restriction reduces the sample size by an additional $10 \%$.

The resulting "in-scope" dataset contains 69,910 schools or about $70 \%$ of all schools that we manage to match to the CCD + PSS dataset. Recall that the sample of matched schools is itself 
a subsample of the CCD + PSS dataset (see previous section). One concern is that the data is becoming less representative of the universe of schools. In particular, smaller schools and/or schools in areas where SG has lower coverage are likely to have more noisy visits data. As a result, these schools are less likely to be included in our dataset of school visits.

To address the potential concern about the representativeness of the remaining sample, we construct sampling weights for schools included in the in-scope data set. We estimate a Probit model where the regressors are school size (as measured by student enrollment) interacted with school covariates (public/private, Charter/non-Charter, locale area type) and Census divisions, and the left-hand side variable is an indicator $y_{j}$ that takes the value of 1 if school $j$ is included in the dataset of school visits and is 0 otherwise. Then, we weight each public school by the inverse of $\hat{\operatorname{Pr}}\left\{y_{j}=1\right\}$, and each private school by its PSS sampling weight times the inverse of $\hat{\operatorname{Pr}}\left\{y_{j}=1\right\}$. We check the quality of this adjustment by comparing the weighted counts of students, teachers, and schools in the data to the counts reported in the NCES digest of education's statistics (i.e. those reported in Table 35 below). 
Table 35: Comparison to the NCES digest of education's statistics

\begin{tabular}{|c|c|c|}
\hline \multicolumn{3}{|c|}{ Number of educational institutions } \\
\hline & NCES table 105.50 & CCD \& PSS \\
\hline Public Schools & 98,469 & 101,688 \\
\hline Elementary & 67,408 & 68,953 \\
\hline Secondary & 23,882 & 21,434 \\
\hline Combined & 6,278 & 6,678 \\
\hline Other $\left(^{a}\right)$ & 901 & 4,623 \\
\hline Private Schools & 32,461 & 27,641 \\
\hline Elementary & 20,090 & 17,378 \\
\hline Secondary & 2,845 & 2,301 \\
\hline Combined & 9,526 & 7,962 \\
\hline All & 130,930 & 129,329 \\
\hline \multicolumn{3}{|c|}{ Number of students (in 1,000s) } \\
\hline & NCES table 105.20 & CCD \& PSS \\
\hline Public Schools $\left({ }^{b}\right)$ & 50,686 & 50,834 \\
\hline Prekindergarten to grade 8 & 35,496 & 33,415 \\
\hline Grades 9 to 12 & 15,190 & 17,419 \\
\hline Private Schools & 5,720 & 4,090 \\
\hline Prekindergarten to grade 8 & 4,252 & 3,450 \\
\hline Grades 9 to 12 & 1,468 & 0.639 \\
\hline All & 56,406 & 54,924 \\
\hline \multicolumn{3}{|c|}{ Number of teachers (in 1,000s, full-time equivalents) } \\
\hline & NCES table $105.40\left(^{(}\right)$ & CCD \& PSS \\
\hline Public Schools & 3,170 & 2,911 \\
\hline Private Schools & 482 & 401 \\
\hline All & 3,652 & 3,312 \\
\hline
\end{tabular}

Notes: NCES numbers refer to the year 2017-2018. $\left({ }^{a}\right)$ Includes special education, alternative, and other schools not classified by grade span. $\left(^{b}\right)$ NCES enrollment numbers in public schools include imputations for public school prekindergarten enrollment in California and Oregon.

\section{B.2 Details of the Burbio Data}

Burbio is a private company that collects data on public schools' calendars for commercial use and for research purposes. The Burbio data contains, for 3,124 counties, weekly indicators of the main learning mode of public schools within a country, categorized as traditional, hybrid, or virtual. These indicators are created by first auditing school districts' websites, Facebook pages, etc. to determine the main learning mode currently in place at the school district level, and then aggregating up to the county level by taking the average of the indicators weighted by student enrollment in each school district. This approach is relevant because public education at the local 
level is organized by school districts. For the most highly populated counties, Burbio samples school districts that represent an average of $90 \%$ of students in those counties. For less populated counties, Burbio adapts its methodology to ensure that its indicators are representative of the learning mode in place for the majority of students enrolled in public schools in those counties. See https://about.burbio.com/methodology/for details about Burbio's methodology.

Burbio shares with us a county-level weekly panel of its indicators. In addition to indicators about traditional, hybrid, and virtual learning, the data contains information on the usual start week of most schools within each county, which we take into account while constructing measurements of the fractions of the schooling year 2020-2021 that a given country spends in a given learning mode. In about one third of the counties, schools usually open before the last week of August; another one third usually opens during the last week of August; and the remainder usually opens some time later in September. 